\title{
Selective side-chain oxidation of alkyl aromatic compounds catalyzed by cerium modified silver catalysts
}

Matthias J. Beier ${ }^{\mathrm{a}}$, Bjoern Schimmoeller ${ }^{\mathrm{b}}$, Thomas W. Hansen ${ }^{\mathrm{c}}$, Jens E. T. Andersen ${ }^{\mathrm{d}}$, Sotiris E. Pratsinis ${ }^{\mathrm{b}}$ and Jan-Dierk Grunwaldt $\mathrm{t}^{\mathrm{a},{ }^{*}}$

${ }^{a}$ Department of Chemical and Biochemical Engineering, Technical University of Denmark, Søltofts Plads Building 229, DK-2800 Kgs. Lyngby, Denmark

${ }^{b}$ Particle Technology Laboratory, Institute of Process Engineering, Department of Mechanical and Process Engineering, ETH Zürich, Sonneggstrasse 3, CH-8092 Zürich, Switzerland

${ }^{c}$ Center for Electron Nanoscopy, Technical University of Denmark, Fysikvej Building 307, DK-2800 Kgs. Lyngby, Denmark

${ }^{d}$ Department of Chemistry, Technical University of Denmark, Kemitorvet Building 207, DK-2800 Kgs. Lyngby, Denmark

${ }^{e}$ Institute for Chemical Technology and Polymer Chemistry, Karlsruhe Institute of Technology (KIT), Engesserstr. 20, D-76131 Karlsruhe, Germany

\footnotetext{
* Corresponding author. Fax: +49 721608 4820. E-mail address: grunwaldt@kit.edu (J.-D. Grunwaldt).
} 


\begin{abstract}
Silver supported on silica effectively catalyzes the aerobic side chain oxidation of alkyl aromatic compounds under solvent-free conditions. Toluene, $p$-xylene, ethylbenzene and cumene were investigated as model substrates. Typically, the reaction was performed at ambient pressure; only for toluene an elevated pressure was required. Carboxylic acids, such as benzoic acid or $p$-toluic acid, additionally increased the reaction rate while $\mathrm{CeO}_{2}$ could act both as a promoter and an inhibitor depending on the substrate and the reaction conditions. Silver catalysts were prepared both by standard impregnation and flame spray pyrolysis. Addition of a Ce precursor to the FSP catalyst resulted in significantly smaller silver particles. Ce-doped FSP catalysts in general exhibited a superior catalytic performance with TONs up to 2000 except for cumene oxidation that appeared to proceed mainly by homogeneous catalysis. In addition, flame-made catalysts were also more stable against silver leaching compared to the impregnated catalysts. The structure of the silver catalysts was studied in detail both by X-ray absorption spectroscopy and transmission electron microscopy suggesting metallic silver to be required for catalytic activity. Catalytic studies point to a radical mechanism which differs depending on the type of substrate.
\end{abstract}

Keywords: selective aerobic oxidation, silver catalysis, flame spray pyrolysis, $p$-xylene, homogeneous vs. heterogeneous catalysis. 


\section{Introduction}

Selective catalytic oxidation by inexpensive reagents such as oxygen, hydrogen peroxide or $t$-butyl hydroperoxide is a viable way of introducing functional groups and thereby upgrading saturated and unsaturated hydrocarbons [1-3]. Finding catalytic systems for these oxidation reactions is of significant industrial importance [4], e.g. for $p$-xylene and cyclohexane oxidation to terephthalic acid and adipinic acid, respectively, which are monomers for commodity polymers [5]. The high industrial impact is also reflected by the large amount of related patent literature [e.g. 6-8]. Nevertheless, these catalytic oxidation reactions still require harsh conditions in industry [4]. As an example, a very effective but highly corrosive and environmentally harmful homogeneous $\mathrm{Co} / \mathrm{Mn} / \mathrm{Br}$ system is employed for $p$-xylene oxidation [9] in liquid phase using acetic acid as solvent which is partly decomposed during reaction. The oxidation follows a radical chain mechanism with the transition metal promoting the chain initiation and the decomposition of peroxo-species [4,9].

Active catalysts for the selective side-chain oxidation of alkyl aromatic compounds are reported mainly for liquid phase oxidations. Only a few examples are reported in the gas phase [10-12] or in supercritical media $[13,14]$. The selective liquid phase oxidation can be conducted both homogeneously and heterogeneously involving mostly metals with two or more stable oxidation states typically under acidic conditions. Most catalytic systems are based on Co often modified with $\mathrm{Mn}$ and a $\mathrm{Br}$ source $[9,15,16]$ but other examples based on e.g. Pt [17] and $\mathrm{Cu}[18,19]$ are also known. Typical oxidizing agents are organic peroxides, hydrogen peroxide, and oxygen offering a cost-effective route to important industrial intermediates such as benzoic acid, acetophenone, benzophenone, toluic acid etc. [5]. Interestingly, ring and side chain oxidation can be controlled by the choice of oxidant $[20,21]$. Due to the relative inertness of the corresponding $\mathrm{C}-\mathrm{H}$ bonds, the reactions are often performed at high pressure and in an additional solvent. Avoiding elevated pressure and working under neat conditions would be the next step to render the oxidation process more cost-efficient. 
Based on the homogeneous $\mathrm{Co} / \mathrm{Mn} / \mathrm{Br}$ system used in the Amoco process many heterogeneous catalysts employ Co as a catalytically active metal. We were interested in the potential of silver as an active material as we showed recently that silver is a potent oxidation catalyst for the selective liquid phase oxidation of alcohols when used in combination with $\mathrm{CeO}_{2}$ nanoparticles [22]. The impregnation route for catalyst synthesis afforded a broad silver particle size distribution with particles ranging from a few $\mathrm{nm}$ up to $50 \mathrm{~nm}$. Flame spray pyrolysis (FSP) has extensively been studied for the preparation of different metal oxide catalysts $[23,24]$ as well as supported noble metal catalysts often affording high metal dispersions with particle sizes of less than $5 \mathrm{~nm}$ on the support [25]. In this way, a good mixing of the oxide particles can be achieved. Therefore, we prepared in the present study the $\mathrm{Ag} / \mathrm{SiO}_{2}-\mathrm{CeO}_{2}$ catalyst system not only by impregnation but also by single-step flame spray pyrolysis and investigated its potential for synthesis of catalysts for the oxidation of aryl aromatic compounds. Comparing $\mathrm{Ag} / \mathrm{CeO}_{2}-\mathrm{SiO}_{2}$ catalysts made by these two routes, the FSP-made catalysts exhibited an improved performance even at significantly lower silver loadings for the oxidation of toluene, $p$-xylene, ethylbenzene and cumene. The structure was further elucidated by X-ray absorption spectroscopy (XAS) and transmission electron microscopy (TEM).

\section{Experimental}

\subsection{Catalyst synthesis}

The impregnated catalyst was prepared by adding $25.0 \mathrm{~mL}$ of an aqueous $\mathrm{AgNO}_{3}$ (Fluka, $>99.5 \%$ ) solution (31 mg/mL) to $5.00 \mathrm{~g}$ of $\mathrm{SiO}_{2}$ (Aerosil 200, Degussa, $200 \mathrm{~m}^{2} / \mathrm{g}$ ) resulting in a $\mathrm{Ag}: \mathrm{SiO}_{2}$ ratio of 1:10. The mixture was stirred with a glass rod and sonicated for $1 \mathrm{~h}$. After drying at $80^{\circ} \mathrm{C}$ for $24 \mathrm{~h}$ the catalyst was calcined in air at $900{ }^{\circ} \mathrm{C}$ for $1 \mathrm{~h}$ in a muffle oven controlled by a Eurotherm 904 controller. The catalyst is denoted as ${ }^{\mathrm{imp}} 10 \% \mathrm{Ag} / \mathrm{SiO}_{2}-900$. 
For catalysts made by flame spray pyrolysis, silver nitrate (Fluka, $>99.5 \%$ ) dissolved in ethanol (EtOH) and diethyleneglycol-monobutylether (DEGME, Fluka, $>98 \% ; 1: 1, \mathrm{Ag} 0.5 \mathrm{M}$ ), hexamethylsiloxane (HMDSO, Fluka $>98 \%$ ) and cerium-2-ethylhexanoate (40\% Ce w/v, Strem) were used as silver, silica and ceria precursors, respectively. The appropriate amounts of the above mentioned precursor solutions were mixed with solvents, i.e. DEGME (Fluka, >98\%) and 2-ethylhexanoic acid (Aldrich, $>98 \%$ ) while keeping the solvent composition constant at 1:1 by volume. The total support metal $(\mathrm{Si}+\mathrm{Ce})$ concentration was kept constant at $0.6 \mathrm{M}$ in these solutions. The nominal $\mathrm{CeO}_{2}$ weight fraction in the product powder ranged from 0 to $50 \mathrm{wt.-} \%$. The silver precursor was added accordingly to reach a nominal $1 \mathrm{wt.}$ - $\%$ $\mathrm{Ag}$ loading in the final powder product. The $\mathrm{Ag} / \mathrm{CeO}_{2}-\mathrm{SiO}_{2}$ powders were produced in a laboratory scale FSP reactor as described elsewhere [26]. The liquid and dispersion gas feed rate were kept constant at 5 $\mathrm{mL} / \mathrm{min}$ and of $5 \mathrm{~L} / \mathrm{min}$, respectively. The pressure drop above the nozzle was adjusted to 1.7 bar and a sheath gas flow of $5 \mathrm{~L} / \mathrm{min} \mathrm{O}_{2}$ was applied through a metal ring $(11 \mathrm{~mm}$ i.d., $18 \mathrm{~mm}$ o.d.) with 32 holes $(0.8$ $\mathrm{mm}$ i.d.) to ensure complete combustion of the precursor. The powders were collected with the aid of a vacuum pump (Busch SV $1025 \mathrm{~B}$ ) on a glass microfiber filter (Whatman GF/D, $257 \mathrm{~mm}$ in diameter). The catalysts are denoted as ${ }^{\mathrm{FSP}} 1 \% \mathrm{Ag} / \mathrm{SiO}_{2} \quad{ }_{\mathrm{FSP}} 1 \% \mathrm{Ag} / 10 \% \mathrm{CeO}_{2}-\mathrm{SiO}_{2}, \quad{ }^{\mathrm{FSP}} 1 \% \mathrm{Ag} / 30 \% \mathrm{CeO}_{2}-\mathrm{SiO}_{2}$ and ${ }^{\mathrm{FSP}} 1 \% \mathrm{Ag} / 50 \% \mathrm{CeO}_{2}-\mathrm{SiO}_{2}$, respectively. Details are given in Table 1.

\subsection{Catalyst testing}

Catalyst tests were performed in a three-necked flask equipped with a gas inlet and a reflux condenser with p-xylene (Sigma-Aldrich $>99 \%$ ), ethylbenzene (Fluka, $>99 \%$ ) or cumene (Fluka, 98\%) as substrates with and without $\mathrm{CeO}_{2}$ nanoparticles (Aldrich, $<25 \mathrm{~nm}$ ), and benzoic acid (Sigma-Aldrich, 99\%) or $p$-toluic acid (Aldrich, 98\%). In a typical experiment the flask was charged with $122 \mathrm{mmol}$ of alkyl aromatic compound and $100 \mathrm{mg}$ biphenyl (Sigma-Aldrich, 99.5\%) as internal standard. Biphenyl was unreactive under the applied reaction conditions, i.e. its presence did not give any additional peaks in the gas chromatogram. The flask was equipped with a magnetic stirring bar and placed in an oil bath heated to $140{ }^{\circ} \mathrm{C}$ which led to a temperature of the reaction mixture of ca. $135^{\circ} \mathrm{C}$. The mixture was saturated with oxygen (Linde, $99.95 \%$ ) 
via the gas inlet and equilibrated for $1.5 \mathrm{~h}$ to ensure a uniform standard and substrate distribution. Benzoic acid (0.45 g, $3.7 \mathrm{mmol}, 3.0 \mathrm{~mol}-\%$ with respect to the hydrocarbon; for ethylbenzene and cumene oxidation) and $p$-toluic acid $(0.50 \mathrm{~g}, 3.7 \mathrm{mmol}, 3.0 \mathrm{~mol}-\%$ with respect to the hydrocarbon; for $p$-xylene oxidation), respectively, were added. After 5 min a sample was taken for GC analysis and the reaction was started by adding $100 \mathrm{mg}$ catalyst and optionally $50 \mathrm{mg} \mathrm{CeO}$ (Aldrich, $<25 \mathrm{~nm}$ ) for catalysts not already containing $\mathrm{CeO}_{2}$.

Analysis was carried out after $1 \mathrm{~h}, 2 \mathrm{~h}$ and $3 \mathrm{~h}$, respectively, by means of an Agilent $6890 \mathrm{~N}$ gas chromatograph equipped with a 7683 B series autosampler, a flame ionization detector and a HP-5 column using biphenyl as internal standard. The following temperature programs were used for product analysis: inlet temperature $250{ }^{\circ} \mathrm{C}$; oven: $110^{\circ} \mathrm{C}$, hold for $10 \mathrm{~min}$; ramp to $120^{\circ} \mathrm{C}\left(5^{\circ} \mathrm{C} / \mathrm{min}\right)$; ramp to $300{ }^{\circ} \mathrm{C}(40$ ${ }^{\circ} \mathrm{C} / \mathrm{min}$ ); $300{ }^{\circ} \mathrm{C}, 2 \mathrm{~min}$; the analysis of hydroperoxides was performed at lower temperatures to ensure minimal decomposition during analysis: inlet temperature $100{ }^{\circ} \mathrm{C}$; oven: $80^{\circ} \mathrm{C}$, hold for $10 \mathrm{~min}$; ramp to 120 ${ }^{\circ} \mathrm{C}\left(5^{\circ} \mathrm{C} / \mathrm{min}\right)$; ramp to $300{ }^{\circ} \mathrm{C}\left(40{ }^{\circ} \mathrm{C} / \mathrm{min}\right) ; 300{ }^{\circ} \mathrm{C}, 2 \mathrm{~min}$. Products were identified by GC-MS. Individual response factors were obtained from commercial compounds, i.e. cumene hydroperoxide (Aldrich, $80 \%$ in cumene), p-methyl benzyl alcohol (Aldrich, 98\%, p-methyl benzaldehyde (Aldrich, 97\%), benzaldehyde (Aldrich, >99\%), benzyl alcohol (SAFC, >99\%), 2-phenyl-2-propanol (Aldrich, 97\%), acetophenone (Aldrich, 99\%) and 1-phenyl ethanol (Aldrich, 98\%). Ethylbenzene hydroperoxide was synthesized according to ref. [27] and the response factor determined from a mixture of 1-phenylethanol and ethylbenzene hydroperoxide.

Since starting material was lost during the reaction despite using reflux condensers, yields rather than conversions and selectivities are presented from which TONs are calculated on the basis of the total amount of silver. In general, results were reproducible within an error margin of 5-10\%. Toluene required higher temperatures than its boiling point, thus, toluene oxidation was done in an autoclave view cell (NWA GmbH, Lörrach). The autoclave was charged with $13.0 \mathrm{~mL}$ toluene (122 mmol), $100 \mathrm{mg}$ biphenyl, $0.45 \mathrm{~g}$ benzoic acid, $50 \mathrm{mg} \mathrm{CeO} 2$ and $100 \mathrm{mg}{ }^{\mathrm{imp}} 10 \% \mathrm{Ag} / \mathrm{SiO}_{2}-900$. A sample for $\mathrm{GC}$ analysis was taken, the autoclave was 
sealed and the $50 \mathrm{~mL}$ residual volume charged with air (10 bar, $\left.4.2 \mathrm{mmol} \mathrm{O}_{2}\right)$. The autoclave was heated up while stirring. After $1 \mathrm{~h}$ at the desired temperature the autoclave was cooled and opened after carefully releasing the overpressure followed by sampling for GC analysis.

\subsection{Catalyst characterization}

X-ray absorption near edge structure (XANES) / extended X-ray absorption fine structure (EXAFS): X-ray absorption spectroscopy (XAS) was measured at beamline X1 at the Hamburger Synchrotronstrahlungslabor (HASYLAB) at the Deutsche Elektronen-Synchrotron (DESY, Hamburg). XAS spectra for silver were recorded in step-scanning mode around the Ag-K edge $(\mathrm{E}=25.514 \mathrm{keV})$ with a $\mathrm{Si}(311)$ double crystal monochromator in transmission mode and a silver foil for energy calibration. EXAFS spectra were processed by energy-calibration, background subtraction, deglitching, normalization and Fourier-transformed after $\mathrm{k}^{3}$ weigthing using the WinXAS 3.1 software [28]. EXAFS data fitting was performed in R-space taking only single scattering paths within the first Ag-Ag or Ag-O shells into account. EXAFS data were fitted with a damping factor obtained from silver foil of 0.85 . Scattering amplitudes and phase shifts were calculated with the FEFF 7.0 code [29].

X-ray diffraction (XRD): The XRD patterns were collected with an X'Pert PRO Diffractometer (PANalytical) with a Cu- $\mathrm{K}_{\alpha} \mathrm{X}$-ray source operated at $45 \mathrm{kV}$ and $40 \mathrm{~mA}$ equipped with a Ni filter and a slit. Diffractograms were recorded between $2 \theta\left(\mathrm{Cu}-\mathrm{K}_{\alpha}\right)=20^{\circ}$ to $90^{\circ}$ with a step width of $0.00164^{\circ}$. The crystallite size was estimated from Rietveld refinement using a Windows-adapted version of the LHMP program [30].

Inductively-coupled plasma mass spectrometry (ICP-MS): The concentrations of cerium and silver in solution were measured by ICP-MS (Perkin-Elmer Elan 6000) equipped with a cross-flow nebulizer. The plasma Ar flow was set to $13 \mathrm{~L} / \mathrm{min}$ at $800 \mathrm{~W}$ RF power and the nebulizer Ar flow was set to $0.80 \mathrm{~L} / \mathrm{min}$. The sample solution was injected at a flow rate of $3.0 \mathrm{~mL} / \mathrm{min}$. Quantification of Ce and $\mathrm{Ag}$ was performed by using multielement ICP-MS standard solutions (Fluka). Samples for ICP-MS were prepared via filtering 
of a hot solution obtained after $3 \mathrm{~h}$ reaction time through preheated celite. An aliquot of $1.0 \mathrm{~mL}$ of the filtrate was taken. Volatile compounds were removed at $120{ }^{\circ} \mathrm{C}$ in vacuo overnight. The residual was treated with $3.5 \mathrm{~mL}$ concentrated $\mathrm{HNO}_{3}$ (Merck, p.a.), $0.5 \mathrm{~mL} \mathrm{HCl}$ (Merck, p.a.) followed by $2 \mathrm{~mL}$ double distilled water and digestion in an Anton Paar Microwave Digestion System Multiwave 3000. The solution was neutralized with ammonium hydroxide solution (Sigma-Aldrich, 28-30\%), filtered, and diluted with distilled water. The overall dilution ratio was 1:500.

Gas adsorption: The specific surface area (SSA) of the catalyst particles were determined by $\mathrm{N}_{2}$ adsorption at 77K using the BET method (Micromeritics Tristar 3000, 5-point isotherm, $0.05<\mathrm{p} / \mathrm{p} 0<0.25$ ).

Transmission electron microscopy (TEM): TEM images were acquired on an FEI Tecnai T20 microscope equipped with a W-filament as electron source operated at 200kV. HRTEM images were taken on an FEI Titan 80-300 microscope operated at $300 \mathrm{kV}$. Catalyst samples were dispersed in dry form on lacey carbon

film supported on $\mathrm{Cu}$ grids. Sample agglomerates overlapping the holes in the support film were imaged using a Gatan US1000 CCD camera. Crystal lattice spacings and particle sizes were analyzed using the Digital Micrograph version GMS 1.8 software package from Gatan Inc.

\section{Results and discussion}

3.1 Catalytic side chain oxidation of p-xylene by $\mathrm{Ag} / \mathrm{SiO}_{2}$ prepared by impregnation

The oxidation of $p$-xylene with an impregnated silica supported $\mathrm{Ag}$ catalyst $\left({ }^{\mathrm{imp}} 10 \% \mathrm{Ag} / \mathrm{SiO}_{2}-900\right)$ in the absence of any solvent resulted in the formation of $p$-methylbenzyl alcohol, $p$-methylbenzaldehyde and $p$ toluic acid at about $3 \%$ yield at $140{ }^{\circ} \mathrm{C}$ after $3 \mathrm{~h}$ (Scheme 1 and Fig. 1) which corresponds to a TON of 43 based on the overall amount of silver. Note, that at this point TONs only serve as a performance comparison being microscopically seen not relevant as the reaction is presumably based on a radical autoxidation mechanism. The addition of $\mathrm{CeO}_{2}$ nanoparticles and a carboxylic acid more than doubled the overall 
catalytic performance resulting in a combined yield of $7 \%$ after $3 \mathrm{~h}$ (TON 100). No difference between benzoic acid and $p$-toluic acid could be found with respect to the catalytic performance (Table 2, entry 1 and 2). As underlined by reaction scheme 1 the second methyl group remained untouched due to the deactivating effect of the electron withdrawing substituent. Some $p$-xylene hydroperoxide as an intermediate reaction product was also observed (less than $0.5 \%$ ) but no pertoluic acid. Note that the reaction proceeded in the absence of light in contrast to other examples found in literature [31,32]. Figure 2 depicts the typical development of the products during the reaction. After a short induction period p-methylbenzyl alcohol and p-methylbenzaldeyhde were formed at approximately the same rate. Hence, both compounds are presumably formed simultaneously and hardly by successive oxidation. The formation of $p$-toluic acid was first detected after an induction period. Thus, p-toluic acid was formed via one (or more) of the intermediates, e.g. by reaction between aldehyde and peroxide.

Silver has a complex interaction with oxygen influencing the catalytic properties [33,34]. Different silver oxygen species can be formed in an oxygen containing atmosphere depending on the calcination temperature $[35,36]$. Therefore, we studied the effect of the calcination temperature on the catalytic performance (Fig. 3). Within the temperature range investigated, the highest calcination temperature, i.e. $900{ }^{\circ} \mathrm{C}$ resulted in the most active silver catalyst with a significant increase in catalytic activity between 600 and $700{ }^{\circ} \mathrm{C}$. After the high temperature treatment rather large silver particles with an average crystal size of $43 \mathrm{~nm}$ were observed from XRD analysis (not shown). These most active catalysts were used during further parametric studies. Extended X-ray absorption spectroscopy (EXAFS) revealed that silver was metallic (Fig. 4) with no indication of oxidized silver suggesting metallic silver to be the active species. The $1^{\text {st }}$ shell silver-silver coordination number of 12 obtained from EXAFS data fitting is in line with metallic silver particles $>5 \mathrm{~nm}$ and corroborates the XRD data. Calcination at $500{ }^{\circ} \mathrm{C}$ was previously investigated [22] and resulted in a lower coordination number of 7.9 despite several large silver particles observed. 
As described before, $\mathrm{CeO}_{2}$ nanoparticles and carboxylic acid addition generally had a beneficial effect on the catalytic performance yielding more of the product acid. Also initial addition of the carboxylic acid only had a beneficial effect. Adding, however, $\mathrm{CeO}_{2}$ nanoparticles alone to ${ }^{\mathrm{imp}} 10 \% \mathrm{Ag} / \mathrm{SiO}_{2}{ }^{-}$ 900 resulted in the formation of hardly any reaction products (Fig. 1). This pinpoints to a radical autoxidation mechanism which is suppressed by $\mathrm{CeO}_{2}$ nanoparticles known to have radical scavenger properties $[37,38]$. This is an intriguing feature of ceria since it both promotes non-radical oxidations $[22,39,40]$ and is capable of increasing the selectivity by suppressing reactive radical species. Further evidence for a radical mechanism was found by suppression of p-xylene oxidation by either 2,6-di(tert.-butyl)phenol or 2,2,6,6tetramethylpiperodine-1-oxyl (TEMPO) which can act as a radical scavenger [41]. When investigating the $\mathrm{Ag} / \mathrm{SiO}_{2}-\mathrm{CeO}_{2}$-carboxylic acid system with the impregnated catalyst for leaching, the cerium concentration was below the limit of detection of $0.1 \mathrm{mg} / \mathrm{L}$. In addition, a reaction mixture treated with $\mathrm{CeO}_{2}$ and carboxylic acid for several hours did not show the promoting effect after filtration of $\mathrm{CeO}_{2}$ and addition of the silver catalyst. Hence there is no indication for soluble cerium species to be responsible for the promoting effect. It must be added, however, that soluble $\mathrm{Ce}^{3+}$ (from $\mathrm{Ce}(\mathrm{III})$ ethylhexanoate) indeed promoted the reaction at a high concentration of $10 \mathrm{mg} / \mathrm{L}$ also in the absence of carboxylic acid to result in an overall product yield of $9.5 \%$ or a TON of 140 with respect to silver. In contrast to the Ce concentration being below the limit of detection, a high silver concentration of $83 \mathrm{mg} / \mathrm{L}$ was found and raises the question whether silver promotes the oxidation reaction homogeneously or heterogeneously. Further tests showed that under non-reactive conditions, i.e. in the absence of carboxylic acid but with $\mathrm{CeO}_{2}$, no silver leaching was observed (Ag concentration $<1 \mathrm{mg} / \mathrm{L}$ ). Hence, leaching is caused by the carboxylic acid and/or the reaction products. Removal of the catalyst by hot filtration almost completely stopped the catalytic reaction. Furthermore, the reaction was performed with silver benzoate as a soluble silver source instead of ${ }^{\mathrm{imp}} 10 \% \mathrm{Ag} / \mathrm{SiO}_{2}-900(\mathrm{Ag}$ silver concentration of $300 \mathrm{mg} / \mathrm{L}$ ). Despite the higher silver concentration compared to the leaching experiment, an overall yield of only $1.6 \%$ was obtained compared to $7.0 \%$ with ${ }^{\mathrm{imp}} 10 \% \mathrm{Ag} / \mathrm{SiO}_{2}-900$.

\subsection{Comparison of impregnated catalysts with flame spray pyrolysis (FSP) derived catalysts}


$\mathrm{Ag} / \mathrm{SiO}_{2}$ has been prepared previously by FSP resulting in rather large silver particles [42]. We prepared a number of $\mathrm{CeO}_{2}-\mathrm{SiO}_{2}$ supported silver catalysts without and with 10,30 and 50 wt.- $\% \mathrm{CeO}_{2}$ (Table 1). An increasing fraction of $\mathrm{CeO}_{2}$ decreased the surface area from $293 \mathrm{~m}^{2} / \mathrm{g}$ without $\mathrm{CeO}_{2}$ to $152 \mathrm{~m}^{2} / \mathrm{g}$ with $50 \%$ $\mathrm{CeO}_{2}$ and additionally the ceria particle size increased with the ceria loading from 3 to $8 \mathrm{~nm}$ (obtained from XRD). High silver loadings of 5-10 wt.-\% gave silver particles around $10 \mathrm{~nm}$ achieving only low overall yields of less than $2 \%$ in the oxidation of $p$-xylene (not shown). No silver diffractions were found in the XRD patterns for $\mathrm{CeO}_{2}-\mathrm{SiO}_{2}$ materials with $1 \mathrm{wt.}$ - $\%$ silver loading due to the low concentration. When tested for catalytic activity in the oxidation of $p$-xylene, FSP catalysts containing $\mathrm{CeO}_{2}$ both gave higher TONs and higher product yields than the impregnated catalyst (Table 2, cf. entries 4, 6, 7 with entry 1) with ${ }^{\mathrm{FSP}} 1 \% \mathrm{Ag} / 10 \% \mathrm{CeO}_{2}-\mathrm{SiO}_{2}$ as the most active catalyst (entry 4). Reusing the catalyst indicated catalyst deactivation (entry 5). ${ }^{\mathrm{FSP}} 1 \% \mathrm{Ag} / \mathrm{SiO}_{2}$ hardly gave higher yields (entry 3 ) than those obtained in the absence of silver (entry 8). Leaching studies on the mixtures after reaction with fresh ${ }^{\mathrm{FSP}} 1 \% \mathrm{Ag} / 10 \% \mathrm{CeO}_{2}-\mathrm{SiO}_{2}$ showed that the silver concentration was below the limit of detection $(<1 \mathrm{mg} / \mathrm{L})$ in contrast to the impregnated catalyst ( $83 \mathrm{mg} / \mathrm{L}$, vide supra) even in the presence of carboxylic acid. In addition, the cerium concentration was lower than $0.1 \mathrm{mg} / \mathrm{L}$.

TEM analysis of ${ }^{\mathrm{FSP}} 1 \% \mathrm{Ag} / \mathrm{SiO}_{2}$ indicated large silver particles of up to $50 \mathrm{~nm}$ which might be a cause for the observed inferior catalytic activity (Fig. 5a, b). Silica precursors with silver nitrate tend to form bimodal Ag distributions. Large Ag particles are discussed to form by droplet-to-powder conversion while fine $\mathrm{Ag}$ come from gas-to-powder conversion [26]. TEM images of ${ }^{\mathrm{FSP}} 1 \% \mathrm{Ag} / 10 \% \mathrm{CeO}_{2}-\mathrm{SiO}_{2}(\mathrm{Fig}$. 5c) showed distinct $\mathrm{CeO}_{2}$ nanoparticles with the size in the range as indicated by XRD ( $3 \mathrm{~nm}$, Table 1). Similar morphologies of segregated crystal domains have been observed previously for FSP-made $\mathrm{Ta}_{2} \mathrm{O}_{5} / \mathrm{SiO}_{2}$ [43] and $\mathrm{TiO}_{2} / \mathrm{SiO}_{2}$ made in diffusion flames [44]. The presence of ceria allowed no clear determination of the silver particle size by STEM analysis but no large Ag particles with a size even close to that found for ${ }^{\mathrm{FSP}} 1 \% \mathrm{Ag} / \mathrm{SiO}_{2}$ were observed (Fig. 5d) indicating that the presence of ceria might have hindered the formation of such large $\mathrm{Ag}$ nanoparticles. The stabilizing effect of $\mathrm{CeO}_{2}$ on the silver nanoparticles during 
synthesis might also be one cause for the pronounced difference in catalytic activity between doped and undoped catalysts.

The Ag K-edge EXAFS spectrum of the impregnated catalyst showed mainly $\mathrm{Ag}-\mathrm{Ag}$ backscattering contributions due to the metallic state of silver. In addition to a Ag-Ag shell, the FSP catalysts ${ }^{\mathrm{FSP}} 1 \% \mathrm{Ag} / \mathrm{SiO}_{2}$ and ${ }^{\mathrm{FSP}} 1 \% \mathrm{Ag} / 10 \% \mathrm{CeO}_{2}-\mathrm{SiO}_{2}$ also featured a $\mathrm{Ag}-\mathrm{O}$ shell within the first coordination sphere (Fig. 6). The as-prepared ${ }^{\mathrm{FSP}} 1 \% \mathrm{Ag} / \mathrm{SiO}_{2}$ catalyst showed both contributions of oxidized and reduced silver. The fitted silver-silver distance of $2.84 \AA$ is close to that for bulk metallic silver $(2.89 \AA)$ while the silveroxygen distance was fitted with $2.29 \AA$ (Table 3, entry 2). Similar distances of $2.32 \AA$ (Ag-O) and $2.81 \AA$ (Ag-Ag) were also found for the ceria-doped catalyst ${ }^{\mathrm{FSP}} 1 \% \mathrm{Ag} / 10 \% \mathrm{CeO}_{2}-\mathrm{SiO}_{2}$ (entry 3). The low $\mathrm{Ag}-\mathrm{Ag}$ distance especially in the latter case might be explained by the lattice contraction of metallic $\mathrm{Ag}$ nanoparticles in the low nm-range [45]. The lower $\mathrm{Ag}-\mathrm{Ag}$ coordination number of ${ }^{\mathrm{FSP}} 1 \% \mathrm{Ag} / 10 \% \mathrm{CeO}_{2}-\mathrm{SiO}_{2}$ compared to ${ }^{\mathrm{FSP}} 1 \% \mathrm{Ag} / \mathrm{SiO}_{2}$ is qualitatively in accordance with the smaller particle size found for the doped catalyst with TEM. However, due to the Ag-O contribution no further quantitative conclusions on the particle size can be drawn. The Ag-O distance in the range of $2.3 \AA$ significantly differs from that found in $\mathrm{Ag}_{2} \mathrm{O}$ being $2.047 \AA$ from XRD [46] or $2.07 \AA$ from EXAFS analysis (entry 5). Ag-O bond lengths between $2.2-2.6 \AA$ are typical for silver silicates [47-50]. The high mixing and fast cooling in the flame could facilitate the atomic mixing of $\mathrm{Ag}$ and $\mathrm{Si}$ and so amorphous silver silicate formed under FSP conditions might indeed account for the observed Ag-O shell. Spent ${ }^{\mathrm{FSP}} 1 \% \mathrm{Ag} / 10 \% \mathrm{CeO}_{2}-\mathrm{SiO}_{2}$ (entry 4 ) has a lower but still appreciable catalytic activity compared to fresh catalyst. The Ag-Ag backscattering contribution is higher pointing to partial reduction of silver under reaction conditions indicating that oxidized silver species are at least partly present on the surface and not in the bulk silica. Possibly also sintering of silver nanoparticles $<10 \mathrm{~nm}$ might occur as these are already very mobile at temperatures close to those applied in the catalytic reaction [51].

\subsection{Extension to further alkyl aromatic compounds}


Extending the study to other alkyl aromatic compounds, the oxidation of toluene, ethylbenzene and cumene was investigated. None of the catalysts was able to convert toluene to benzyl alcohol, benzaldehyde or benzoic acid under atmospheric pressure which is likely to be connected to the boiling point of toluene being ca. $30^{\circ} \mathrm{C}$ lower than that of $p$-xylene and the absence of a second presumably activating methyl group. Thus, toluene oxidation was attempted in an autoclave both at $140{ }^{\circ} \mathrm{C}$ and $170{ }^{\circ} \mathrm{C}$ with the impregnated catalyst. Hardly any conversion was found at $140{ }^{\circ} \mathrm{C}$ but at $170{ }^{\circ} \mathrm{C}$ the reaction was completed after $1 \mathrm{~h}$ (Table 4) the limiting factor here being the amount of oxygen present in the reactor. Note that at this temperature thermal toluene autoxidation becomes relevant but proceeds at lower reaction rates [52].

The oxidation of ethylbenzene gave both 1-phenylethanol and acetophenone and additionally ethylbenzene hydroperoxide (Table 5), which are typical products for the radical (aut)oxidation of ethylbenzene [32,53]. Compared to the oxidation of $p$-xylene, the effect of ceria was different. While for $p$ xylene, the impregnated catalyst was most active in the presence of ceria and carboxylic acid, ceria decreased the catalyst activity in the case of ethylbenzene (Fig. 7a). Flame synthesized catalysts gave higher TONs of up to 2000 (Table 5, entry 2) compared to the impregnated catalyst but lower overall product yields.

Cumene oxidation gave mainly cumene hydroperoxide, acetophenone and 2-phenyl-2propanol (Table 6) with minor side products being benzaldehyde and $\alpha$-methyl styrene. The hydroperoxide exhibited transient behavior, i.e. its yield exhibited a maximum after $1-2$ hours in the presence of carboxylic acid and $\mathrm{CeO}_{2}$. Interestingly, FSP catalysts supported on $\mathrm{CeO}_{2}-\mathrm{SiO}_{2}$ generally resulted in lower yields (entries 2-4). Even in the presence of added ceria nanoparticles the obtained yield was higher for ${ }^{\mathrm{imp}} 10 \% \mathrm{Ag} / \mathrm{SiO}_{2}-900$ (entry 1). One of the reasons for this discrepancy might be the close proximity between ceria and silver being the radical initiator for $\mathrm{CeO}_{2}-\mathrm{SiO}_{2}$ supported FSP catalysts and the smaller $\mathrm{CeO}_{2}$ particle size (3-8 nm, Table 1, compared to $25 \mathrm{~nm}$ for the commercial ceria). This may also be the origin for the deactivating effect when adding ceria to ${ }^{\mathrm{imp}} 10 \% \mathrm{Ag} / \mathrm{SiO}_{2}-900$ even in the presence of benzoic acid (Fig. $7 b)$ as observed for ethylbenzene oxidation. Interestingly, flame synthesized silver catalysts with $\mathrm{SiO}_{2}-\mathrm{CeO}_{2}$ 
support gave not only lower overall yields but also an altered product distribution. Only small amounts of alcohol and peroxide were formed (which are the main products in the reactions with the impregnated $\mathrm{Ag}$ catalysts) the main product being acetophenone. These alterations indicate a different reaction mechanism and are probably due to a changing ratio of the reaction rates of chain termination vs. propagation and the suppression of some radical reaction pathways.

When ${ }^{i m p} 10 \% \mathrm{Ag} / \mathrm{SiO}_{2}-900$ was used as a catalyst, the oxidation of ethylbenzene and cumene continued after removal of the solid phase. In case of cumene a silver concentration of $9 \mathrm{mg} / \mathrm{L}$ was found by ICP-MS while for ${ }^{\mathrm{FSP}} 1 \% \mathrm{Ag} / 10 \% \mathrm{CeO}_{2}-\mathrm{SiO}_{2}$ the silver concentration was below the detection limit. This indicates a shift from heterogeneous to homogeneous catalysis and explains also the inferior performance and the different product distribution over the FSP-catalysts that tend to leach less. Note that peroxo species formed during the presence of the catalyst and their higher stability compared to $p$-xylene oxidation may also maintain the reaction to a certain extent.

\subsection{Discussion and mechanistic considerations}

The oxidation of different alkyl aromatic compounds can be promoted by heterogeneous silver catalysts prepared via impregnation or flame spray pyrolysis. Yields are similar to other heterogeneous catalyst systems [19] but there is still a large gap in performance compared to the industrial homogeneous Amoco process. In the case of $p$-xylene and ethylbenzene the FSP catalysts were considerably more active with respect to the Ag loading. In addition, the FSP catalysts exhibited a significantly lower leaching tendency which might originate from a stronger metal-support interaction established during synthesis by combustion of the liquid precursor. In contrast, the impregnated catalyst performed superior in the cumene oxidation and gave another product distribution than the FSP catalysts thus indicating a different mechanism changing from heterogeneous to homogeneous catalysis. 
The suppression of the oxidation reaction by radical scavengers and the formation of hydroperoxides strongly suggest that the investigated $p$-xylene oxidation reaction is based on a radical reaction mechanism, which is supported by many examples from the literature for analogous cases [e.g. 9,54,55]. Radical reactions comprise mainly three steps, namely initiation, radical chain reaction and termination (Scheme 2). The ratio of rate constants for these steps determines the overall catalytic performance and is dependent on the catalyst. Conversion of starting material was already observed when only the impregnated silver catalyst was used. The addition of peroxides to facilitate the start of the reaction as reported in other cases [56] was not necessary. Hence, silver facilitates the formation of initial radicals (Scheme 2, step 1). The chain reaction is likely not to be supported by the silver catalyst, firstly, because the product distribution in the absence of carboxylic acid is typical for uncatalyzed autoxidations [57,58]. In addition, chain propagation is fast compared to initiation. This would also require a catalyst in the same phase as e.g. in case of the homogeneous $\mathrm{Co} / \mathrm{Mn} / \mathrm{Br}$ catalyst system [9] but a correlation between leaching and catalyst activity could not be established for $p$-xylene. Diffusion of the radicals to $\mathrm{Ag}$ particles and $\mathrm{CeO}_{2}$ would be likely to occur in the same time regime so that the rate constants for chain propagation and termination would be similar if chain propagation relies on silver. Silver may, however, play a role in the decomposition of hydroperoxides influencing the radical concentration.

FSP synthesized catalysts featured both metallic silver and Ag-O species which might be reduced under reaction conditions since the used ${ }^{\mathrm{FSP}} 1 \% \mathrm{Ag} / 10 \% \mathrm{CeO}_{2}-\mathrm{SiO}_{2}$ catalyst showed a stronger $\mathrm{Ag}-\mathrm{Ag}$ backscattering in the EXAFS spectrum. Silver in the active impregnated catalyst was found to be only metallic. Thus, metallic silver appears to be required for an active catalyst. The ambivalent influence of ceria suggests that ceria is interacting with two parts of the overall radical reaction one of which is obviously the chain termination (Scheme 2, step 3), since the reaction is suppressed when only ceria and silver catalyst is used. Initiation by silver might be influenced by ceria (Scheme 2, step 1). Ceria is known to activate oxygen [39], which could then support breaking of $\mathrm{C}-\mathrm{H}$ bonds in $p$-xylene which are stronger compared to ethylbenzene and cumene. Thus, $\mathrm{CeO}_{2}$ has no beneficial effect in the latter cases. Additionally, the latter 
more stable peroxo radicals [59] might have a longer half life which makes quenching by scavengers, which $\mathrm{CeO}_{2}$ is, more likely. Molecular oxygen does not play a dominant role in the radical chain reaction since the reaction of alkyl radicals with molecular oxygen is fast [57]. Addition of carboxylic acid did not only increase the overall yield but also influenced the product distribution and hence changed the overall mechanism either directly via the propagation mechanism [54] (Scheme 2, step 2) or via destabilization of the termination product, i.e. the hydroperoxide, in the presence of radicals [60]. Indeed, in the case of $p$ xylene, ethylbenzene and cumene oxidation the hydroperoxide exhibited transient behavior. A higher degree of hydroperoxide dissociation would also result in a higher radical concentration which explains why not only the product distribution was shifted but also a higher overall yield was obtained. The higher O-H bond dissociation energies (BDE) of benzoic acid and toluic acid compared to the $\mathrm{C}-\mathrm{H}$ BDE of alkyl aromatic compounds and the $\mathrm{O}-\mathrm{H} \mathrm{BDE}$ of the corresponding peroxides [59] makes the presence of carboxyloxo radical species generated from the added carboxylic acid unlikely. Thus, the carboxylic acids presumably promote the peroxide dissociation. The capability of carboxylic acids to act as an H-bond acceptor can stabilize $\cdot \mathrm{OH}$ radicals [61]. This lowers the activation energy for e.g. peroxide dissociation thereby generating a higher radical concentration and promoting the chain initiation.

Cumene oxidation with FSP synthesized $\mathrm{CeO}_{2}-\mathrm{SiO}_{2}$ supported catalysts proceeded with a low reaction rate and gave mainly acetophenone as a product. This was not the case when ${ }^{\mathrm{imp}} 10 \% \mathrm{Ag} / \mathrm{SiO}_{2}-900$ was used in the presence of ceria nanoparticles, but here leaching of silver is important. In both cases the product distribution differs from typical cumene autoxidations for which the main product is cumene hydroperoxide. Thermal decomposition of the hydroperoxide alone cannot be the reason since in the absence of ceria and benzoic acid cumene hydroperoxide was by far the dominating product. Ceria was used before as a catalyst for alkyl aromatics oxidation with bromate affording the carbonyl compound as the main product [58]. Acetophenone can be formed from cumene hydroperoxide either by reaction with a reducing agent [62] or generation of a hydroxyl radical via cleavage of the oxygen-oxygen bond [57] resulting an intermediate $\alpha, \alpha$-dimethylbenzyloxy radical. According to Bhattacharya et al. [57] this radical preferably 
reacts to form acetophenone. If either one of these reactions is promoted by $\mathrm{CeO}_{2}$ the close proximity between $\mathrm{CeO}_{2}$ particles and silver stable against leaching on the FSP catalysts in the investigated reaction media might be the reason why $\mathrm{CeO}_{2}$ already present on the support showed a more deactivating effect than $\mathrm{CeO}_{2}$ added to the reaction mixture (in case of the impregnated catalyst).

\section{Conclusions}

Silver particles supported on silica effectively promote the side chain oxidation of toluene, $p$-xylene, ethylbenzene and cumene without any solvent. Except for toluene, no elevated pressures were needed to facilitate the reaction. Addition of a carboxylic acid considerably enhanced the reaction rate. $\mathrm{CeO}_{2}$ had an ambivalent influence on the reaction and could both promote and inhibit product formation depending on substrate and reaction conditions. Except for cumene oxidation silver catalysts prepared via impregnation were inferior to flame-made catalysts which gave TONs up to 2000. In addition, the flame-synthesized catalysts were significantly less prone to leaching compared to the impregnated catalyst. This may be exploited in the future to prepare more stable catalysts for liquid phase reactions where leaching should be circumvented. In order to be active, silver is required to be metallic as suggested by EXAFS analysis. The oxidation reaction is most likely based on a radical mechanism where $\mathrm{CeO}_{2}$ possibly assists silver as a chain initiator, while the carboxylic acid influences the dissociation of peroxides to radical species to initiate radical chains. Ceria as a radical scavenger additionally induces chain termination.

\section{Acknowledgements}

Financial support of the study by the Technical University of Denmark (DTU) and the Danish Research Council (FTP-project) as well the support of the PhD grant by DTU, the Graduate School $\mathrm{MP}_{2} \mathrm{~T}$ and Haldor 
Topsøe A/S are gratefully acknowledged. Financial support by ETH Research Grant TH-41 06-1 and discussions with Georgios Sotiriou (ETH Zürich) are gratefully acknowledged. We thank Helge Rasmussen for assistance during the XRD measurements, Evonik Degussa GmbH for donation of support materials and HASYLAB at DESY, Hamburg, for beamtime and financial support (Contract RII13-CT-2004-506008). Birgit Elkjær Ascanius (DTU KT) is acknowledged for providing GC-MS analysis. The A.P. Møller and Chastine Mc-Kinney Møller Foundation is gratefully acknowledged for its contribution towards establishment of Center for Electron Nanoscopy.

\section{References}

[1] J.M. Thomas, R. Raja, Solid State Sci. (2001) 675-687.

[2] J.M. Bregeault, Dalton Trans. (2003) 3289-3302.

[3] T. Punniyamurthy, S. Velusamy, J. Iqbal, Chem. Rev. 105 (2005) 2329-2363.

[4] A.K. Suresh, M.M. Sharma, T. Sridhar, Ind. Eng. Chem. Res. 39 (2000) 3958-3997.

[5] M. Bohnet, Ullmann's encyclopedia of industrial chemistry, seventh ed., Wiley-VCH, Weinheim, 2003.

[6] H.J. Rozie, M.L.C. Dsinter, J.B. Dakka, A. Zoran, Y. Sasson, PCT Int. Appl., 9,520,560 (1995).

[7] M.L. Kantam, B.M. Choudary, P. Sreekanth, K.K. Rao, K. Naik, T.P. Kumar, A.A. Khan, Eur. Pat. Appl., 1,088,810 (2001).

[8] S. Park, J.S. Yoo, K. Jun, D.B. Raju, Y. Kim, U.S. Patent, 6,476,257 (2002).

[9] W. Partenheimer, Catal. Today 23 (1995) 69-158.

[10] V. Kumar, P.D. Grover, Ind. Eng. Chem. Res. 30 (1991) 1139-1141.

[11] G. Busca, J. Chem. Soc., Faraday Trans. 89 (1993) 753-755. 
[12] J.S. Yoo, J.A. Donohue, M.S. Kleefisch, P.S. Lin, S.D. Elfline, Appl. Catal., A 105 (1993) 83-105.

[13] P.A. Hamley, T. Ilkenhans, J.M. Webster, E. Garcia-Verdugo, E. Venardou, M.J. Clarke, R. Auerbach, W.B. Thomas, K. Whiston, M. Poliakoff, Green Chem. 4 (2002) 235-238.

[14] T. Seki, M. Baiker, Chem. Rev. 109 (2009) 2409-2454.

[15] H.V. Borgaonkar, S.R. Raverkar, S.B. Chandalia, Ind. Eng. Chem. Prod. Res. Dev. 23 (1984) 455-458.

[16] M. Hronec, Z. Hrabe, Ind. Eng. Chem. Prod. Res. Dev. 25 (1986) 257-261.

[17] M. Ilyas, M. Sadiq, Catal. Lett. 128 (2009) 337-342.

[18] B. Chou, J. Tsai, S. Cheng, Microporous Mesporous Mater. 48 (2001) 309-317.

[19] F. Wang, J. Xu, X. Li, J. Gao, L. Zhou, R. Ohnishi, Adv. Synth. Catal. 347 (2005) 1987-1992.

[20] R. Raja, J.M. Thomas, V. Dreyer, Catal. Lett. 110 (2006) 179-183.

[21] R. Raja, J.M. Thomas, Solid State Sci. 8 (2006) 326-331.

[22] M.J. Beier, T.W. Hansen, J.-D. Grunwaldt, J. Catal. 266 (2009) 320-330.

[23] R. Strobel, A. Baiker, S.E. Pratsinis, Adv. Powder Technol. 17 (2006) 457-480.

[24] R. Kydd, W.Y. Teoh, K. Wong, Y. Wang, J. Scott, Q. Zeng, A. Yu, J. Zou, R. Amal, Adv. Funct. Mater. 19 (2009) 369-377.

[25] S. Hannemann, J.-D. Grunwaldt, P. Lienemann, D. Guenther, F. Krumeich, S.E. Pratsinis, A. Baiker, Appl. Catal., A 316 (2007) 226-239.

[26] H. Schulz, L. Mädler, R. Strobel, R. Jossen, S.E. Pratsinis, T. Johannessen, J. Mater. Res. 20 (2005) 2568-2577.

[27] J. Yuan, X. Liao, H. Wang, G. Yang, M. Tang, J. Phys. Chem. B. 113 (2009) 1418-1422. 
[28] T. Ressler, J. Synchrotron Radiat. 5 (1998) 118-122.

[29] S.I. Zabinsky, J.J. Rehr, A. Ankudinov, R.C. Albers, M.J. Eller, Phys. Rev. B: Condens. Matter Mater. Phys. 52 (1995) 2995-3009.

[30] R.J. Hill and C.J. Howard, AAEC (now ANSTO), Australian Atomic Commission Report No. M112, $2^{\text {nd }}$ ed., Lucas Heights Research Laboratories, New South Wales, Australia, 1986; winpow was obtained from http://struktur.kemi.dtu.dk/kenny/powder_programs.html, last accessed on April, $16^{\text {th }}, 2010$.

[31] K. Ohkubo, S. Fukuzumi, Org. Lett. 2 (2000) 3647-3650.

[32] G. Sereda, V. Rajpara, Tetrahedron Lett. 48 (2007) 3417-3421.

[33] C. Rehren, G. Isaac, R. Schlögl, G. Ertl, Catal. Lett. 11 (1991) 253-265.

[34] X. Bao, G. Lehmpfuhl, G. Weinberg, R. Schlögl, G. Ertl, J. Chem. Soc. , Faraday Trans. 88 (1992) 865872.

[35] Z.P. Qu, M.J. Cheng, W.X. Huang, X.H. Bao, J. Catal. 229 (2005) 446-458.

[36] Z.P. Qu, W.X. Huang, M.J. Cheng, X.H. Bao, J. Phys. Chem. B. 109 (2005) 15842-15848.

[37] S. Babu, A. Velez, K. Wozniak, J. Szydlowska, S. Seal, Chem. Phys. Lett. 442 (2007) 405-408.

[38] P. Trogadas, J. Parrondo, V. Ramani, Electrochem. Solid-State Lett. 11 (2008) B113-B116.

[39] A. Trovarelli, G.J. Hutchings (Ed.), Catalysis by ceria and related materials, Imperial College Press, London, 2002.

[40] A. Abad, P. Concepcion, A. Corma, H. Garcia, Angew. Chem., Int. Edit. 44 (2005) 4066-4069.

[41] T. Vogler, A. Studer, Synthesis (2008) 1979-1993. 
[42] S. Hannemann, J.-D. Grunwaldt, F. Krumeich, P. Kappen, A. Baiker, Appl. Surf. Sci. 252 (2006) 78627873.

[43] H. Schulz, L. Maedler, S.E. Pratsinis, P. Burtscher, N. Moszner, Adv. Funct. Mater. 15 (2005) 830-837.

[44] A. Teleki, S.E. Pratsinis, K. Wegner, R. Jossen, F. Krumeich, J. Mater. Res. 20 (2005) 1336-1347.

[45] B. Medasani, Y.H. Park, I. Vasiliev, Phys. Rev. B: Condens. Matter Mater. Phys.75 (2007) 235436-1-6.

[46] P. Niggli, Z. Kristallogr., Kristallgeom., Kristallphys. Kristallchem. 57 (1922) 253-299.

[47] F. Liebau, Acta Crystallogr. 14 (1961) 537-538.

[48] M. Jansen, H.L. Keller, Angew. Chem. 91 (1979) 500.

[49] K. Heidebrecht, M. Jansen, Z. Anorg. Allg. Chem. 597 (1991) 79-86.

[50] W. Klein, M. Jansen, Z. Anorg. Allg. Chem. 634 (2008) 1077-1081.

[51] O.A. Yeshchenko, I.M. Dmitruk, A.A. Alexeenko, A.V. Kotko, Nanotechnology 21 (2010) 045203/1$045203 / 6$.

[52] I. Hermans, J. Peeters, L. Vereecken, P.A. Jacobs, ChemPhysChem. 8 (2007) 2678-2688.

[53] T.V. Bukharkina, O.S. Grechishkina, N.G. Digurov, N.V. Krukovskaya, Org. Process Res. Dev. 3 (1999) 400-403.

[54] Y. Kamiya, M. Kashima, Bull. Chem. Soc. Jpn. 46 (1973) 905-908.

[55] Q. Jiang, Y. Xiao, Z. Tan, Q. Li, C. Guo, J. Mol. Catal. A: Chem 285 (2008) 162-168.

[56] P.P. Toribio, A. Gimeno-Gargallo, M.C. Capel-Sanchez, M.P. de Frutos, J.M. Campos-Martin, J.L.G. Fierro, Appl. Catal., A. 363 (2009) 32-39.

[57] A. Bhattacharya, Chem. Eng. J. 137 (2008) 308-319. 
[58] I. Hermans, J. Peeters, P.A. Jacobs, J. Org. Chem. 72 (2007) 3057-3064.

[59] E.T. Denisov, E.V. Tumanov, Russ. Chem. Rev. 74 (2005) 905-938.

[60] C. Wang, H. Chen, C. Chen, Polym. Adv. Technol. 17 (2006) 579-586.

[61] I. Hermans, J. Peeters, P.A. Jacobs, ChemPhysChem 7 (2006) 1142-1148.

[62] H. Boardman, J. Am. Chem. Soc. 75 (1953) 4268-4271. 


\section{Figure captions}

Fig. 1. Influence of carboxylic acid (p-toluic acid) and $\mathrm{CeO}_{2}$ as additives on the oxidation of $p$-xylene. Reaction conditions: $122 \mathrm{mmol} p$-xylene, optionally $3 \mathrm{~mol}-\%$ p-toluic acid and/or $50 \mathrm{mg} \mathrm{CeO}, 100 \mathrm{mg}$ biphenyl, $100 \mathrm{mg}{ }^{\mathrm{imp}} 10 \% \mathrm{Ag} / \mathrm{SiO}_{2}-900$, oxygen atmosphere, $140{ }^{\circ} \mathrm{C}, 3 \mathrm{~h}$ reaction time.

Fig. 2. Formation of $p$-methylbenzyl alcohol $(\bullet), p$-methylbenzaldehyde $(\bullet)$ and $p$-toluic acid $(\Delta)$ during the oxidation of $p$-xylene with ${ }^{\mathrm{FSP}} 1 \% \mathrm{Ag} / 10 \% \mathrm{CeO}_{2}-\mathrm{SiO}_{2}$. Reaction conditions: $122 \mathrm{mmol}$-xylene, $3 \mathrm{~mol}-\%$ benzoic acid, $100 \mathrm{mg}$ biphenyl, $100 \mathrm{mg}{ }^{\mathrm{FSP}} 1 \% \mathrm{Ag} / 10 \% \mathrm{CeO}_{2}-\mathrm{SiO}_{2}$, oxygen atmosphere, $140{ }^{\circ} \mathrm{C}$.

Fig. 3. Yields of $p$-methylbenzyl alcohol, $p$-methylbenzaldehyde and $p$-toluic acid obtained during the oxidation of $p$-xylene with ${ }^{\text {imp }} 10 \% \mathrm{Ag} / \mathrm{SiO}_{2}$ calcined for $1 \mathrm{~h}$ in air at temperatures between $300{ }^{\circ} \mathrm{C}$ and $900{ }^{\circ} \mathrm{C}$ in the presence of ceria and carboxylic acid. Reaction conditions: $122 \mathrm{mmol} p$-xylene, 3 mol- $\% p$-toluenic acid, $100 \mathrm{mg}$ biphenyl, $100 \mathrm{mg}{ }^{\mathrm{imp}} 10 \% \mathrm{Ag} / \mathrm{SiO}_{2}$ calcined in air as indicated, $50 \mathrm{mg} \mathrm{CeO}$, oxygen atmosphere, $140{ }^{\circ} \mathrm{C}, 3 \mathrm{~h}$ reaction time.

Fig. 4. EXAFS spectrum of ${ }^{\mathrm{imp}} 10 \% \mathrm{Ag} / \mathrm{SiO}_{2}$ calcined at $500{ }^{\circ} \mathrm{C}$ (a), at $900{ }^{\circ} \mathrm{C}$ (b) and silver foil (c) recorded at the Ag K-edge. Note the smaller EXAFS oscillation amplitude in (a) compared to (b). Inset: Experimental (solid line) and $1^{\text {st }}$ shell EXAFS data fitted (dashed line) FT EXAFS function of ${ }^{\mathrm{imp}} 10 \% \mathrm{Ag} / \mathrm{SiO}_{2}-900$ from $\mathrm{k}$ $=2-15 \AA^{-1}$.

Fig. 5. TEM images of fresh ${ }^{\mathrm{FSP}} 1 \% \mathrm{Ag} / \mathrm{SiO}_{2}(\mathrm{a}, \mathrm{b})$ and fresh $1 \% \mathrm{Ag} / 10 \% \mathrm{CeO}_{2}-\mathrm{SiO}_{2}(\mathrm{c}, \mathrm{d})$. Dark spots represent silver particles. Circles indicate $\mathrm{CeO}_{2}$ particles.

Fig. 6. EXAFS spectra of flame synthesized ${ }^{\mathrm{FSP}} 1 \% \mathrm{Ag} / \mathrm{SiO}_{2}(\mathrm{a}),{ }^{\mathrm{FSP}} 1 \% \mathrm{Ag} / 10 \% \mathrm{CeO}_{2}-\mathrm{SiO}_{2}$ as prepared (b) and after the reaction (c) the Ag K-edge. Insets: Experimental (solid line) and fitted (dashed line, EXAFS data fitting in R-space) $\mathrm{k}^{3}$-weighted Fourier transformed EXAFS function. 
Fig. 7. Influence of the carboxylic acid and $\mathrm{CeO}_{2}$ on the oxidation of ethylbenzene (a) and cumene (b). Reaction conditions: $122 \mathrm{mmol}$ ethylbenzene or cumene, optionally $3 \mathrm{~mol}-\%$ benzoic acid and $50 \mathrm{mg} \mathrm{CeO}$, $100 \mathrm{mg}$ biphenyl, $100 \mathrm{mg}{ }^{\mathrm{imp}} 10 \% \mathrm{Ag} / \mathrm{SiO}_{2}-900$, oxygen atmosphere, $140{ }^{\circ} \mathrm{C}, 3 \mathrm{~h}$ reaction time. 


\section{Tables}

Table 1. Overview over the silver catalysts prepared by flame spray pyrolysis and impregnation.

\begin{tabular}{|c|c|c|c|c|c|c|c|}
\hline Catalyst & $\begin{array}{c}\mathrm{Ag} \\
\text { (wt.-\%) }\end{array}$ & $\begin{array}{c}\mathrm{CeO}_{2} \\
\text { (wt.-\%) }\end{array}$ & $\begin{array}{c}\mathrm{SiO}_{2} \\
\text { (wt.-\%) }\end{array}$ & $\begin{array}{l}\text { SSA } \\
\left(\mathrm{m}^{2} / \mathrm{g}\right)^{\mathrm{a}}\end{array}$ & $\begin{array}{c}\mathrm{CeO}_{2} \\
\text { crystal } \\
\text { size }^{\mathrm{b}} \\
(\mathrm{nm})\end{array}$ & $\begin{array}{c}\mathrm{Ag} \\
\text { crystal } \\
\text { size }^{\mathrm{b}} \\
(\mathrm{nm})\end{array}$ & Entry \\
\hline${ }^{\mathrm{FSP}} 1 \% \mathrm{Ag} / \mathrm{SiO}_{2}$ & 1 & 0 & 100 & 293 & - & n.d. ${ }^{\mathrm{c}}$ & 1 \\
\hline $\begin{array}{c}{ }^{\mathrm{FSP}} 1 \% \mathrm{Ag} / 10 \% \mathrm{CeO}_{2-} \\
\mathrm{SiO}_{2}\end{array}$ & 1 & 10 & 90 & 273 & 3.3 & - & 2 \\
\hline $\begin{array}{c}{ }^{\mathrm{FSP}} 1 \% \mathrm{Ag} / 30 \% \mathrm{CeO}_{2-} \\
\mathrm{SiO}_{2}\end{array}$ & 1 & 30 & 70 & 194 & 5.8 & - & 3 \\
\hline $\begin{array}{c}\mathrm{FSP}^{\mathrm{F}} \% \mathrm{Ag} / 50 \% \mathrm{CeO}_{2-}- \\
\mathrm{SiO}_{2}\end{array}$ & 1 & 50 & 50 & 152 & 8.3 & - & 4 \\
\hline${ }^{\mathrm{imp}} 10 \% \mathrm{Ag} / \mathrm{SiO}_{2}-900$ & 10 & 0 & 100 & 128 & - & 43 & 5 \\
\hline
\end{tabular}

${ }^{a}$ Determined by nitrogen adsorption. ${ }^{b}$ Determined by XRD. ${ }^{c}$ not detectable. 
Table 2. Oxidation of $p$-xylene with silver catalysts in the presence of $\mathrm{CeO}_{2}$ and carboxylic acid. Reaction conditions: $122 \mathrm{mmol}$-xylene, $3 \mathrm{~mol}-\%$ p-toluic acid, $100 \mathrm{mg}$ biphenyl, $100 \mathrm{mg}$ catalyst, oxygen atmosphere, $140{ }^{\circ} \mathrm{C}, 3 \mathrm{~h}$ reaction time.

\begin{tabular}{|c|c|c|c|c|c|c|}
\hline \multicolumn{7}{|c|}{ Yields (\%) } \\
\hline Catalyst & & & & & $\mathrm{TON}^{\mathrm{a}}$ & Entry \\
\hline imp $10 \% \mathrm{Ag} / \mathrm{SiO}_{2}-900^{\mathrm{b}}$ & 2.1 & 2.1 & 28 & 7.0 & 100 & 1 \\
\hline${ }^{\mathrm{imp}} 10 \% \mathrm{Ag} / \mathrm{SiO}_{2}-900^{\mathrm{c}}$ & 2.0 & 2.0 & 2.8 & 6.8 & 100 & 2 \\
\hline${ }^{\mathrm{FSP}} 1 \% \mathrm{Ag} / \mathrm{SiO}_{2}{ }^{\mathrm{b}}$ & 0.4 & 0.6 & 0.2 & 1.2 & 160 & 3 \\
\hline $\begin{array}{c}\mathrm{FSP}^{\mathrm{C}} \% \mathrm{Ag} / 10 \% \mathrm{CeO}_{2^{-}} \\
\mathrm{SiO}_{2}\end{array}$ & 3.0 & 2.6 & 7.8 & 13.4 & 1800 & 4 \\
\hline $\begin{array}{c}\mathrm{FSP}^{\mathrm{C}} \% \mathrm{Ag} / 10 \% \mathrm{CeO}_{2^{-}} \\
\mathrm{SiO}_{2}{ }^{\mathrm{d}}\end{array}$ & 2.3 & 2.1 & 3.3 & 7.7 & 1000 & 5 \\
\hline 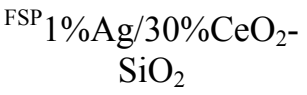 & 2.8 & 2.5 & 5.2 & 10.5 & 1400 & 6 \\
\hline $\begin{array}{c}\mathrm{FSP}^{\mathrm{F}} \% \mathrm{Ag} / 50 \% \mathrm{CeO}_{2^{-}} \\
\mathrm{SiO}_{2}\end{array}$ & 2.4 & 2.2 & 3.8 & 8.4 & 1100 & 7 \\
\hline $\mathrm{SiO}_{2}{ }^{\mathrm{b}}$ & 0.2 & 0.3 & 0.3 & 0.8 & - & 8 \\
\hline
\end{tabular}

${ }^{a}$ Based on the number of product molecules with respect to the total amount of silver during one experiment. ${ }^{\mathrm{b}} 50 \mathrm{mg} \mathrm{CeO} 2$ added. ${ }^{\mathrm{c}} 3$ mol-\% benzoic acid used instead of $p$-toluic acid. ${ }^{\mathrm{d}} 1^{\text {st }}$ re-use. ${ }^{\mathrm{e}}$ Without $\mathrm{CeO}_{2}$ and $p$ toluic acid. 
Table 3. Overview over structural parameters obtained from EXAFS data fitting.

\begin{tabular}{|c|c|c|c|c|c|c|}
\hline Catalyst & Shell & $\mathrm{N}( \pm 0.5)$ & $\mathrm{R}(\AA)$ & $\sigma\left(\AA^{-2}\right)$ & Residual & Entry \\
\hline${ }^{\mathrm{imp}} 10 \% \mathrm{Ag} / \mathrm{SiO}_{2}-900$ & $\mathrm{Ag}-\mathrm{Ag}$ & 12 & 2.86 & 0.010 & 6.7 & 1 \\
\hline \multirow[t]{2}{*}{${ }^{\mathrm{FSP}} 1 \% \mathrm{Ag} / \mathrm{SiO}_{2}$} & $\mathrm{Ag}-\mathrm{O}$ & 1.7 & 2.29 & 0.016 & 1.5 & 2 \\
\hline & $\mathrm{Ag}-\mathrm{Ag}$ & 3.1 & 2.84 & 0.016 & & \\
\hline${ }^{\mathrm{FSP}} 1 \% \mathrm{Ag} / 10 \% \mathrm{CeO}_{2^{-}}$ & Ag-O & 3.8 & 2.32 & 0.022 & 5.1 & 3 \\
\hline $\mathrm{SiO}_{2}$ & $\mathrm{Ag}-\mathrm{Ag}$ & 0.5 & 2.81 & 0.013 & & \\
\hline${ }^{\mathrm{FSP}} 1 \% \mathrm{Ag} / 10 \% \mathrm{CeO}_{2^{-}}$ & Ag-O & 3.1 & 2.28 & 0.030 & 1.7 & 4 \\
\hline $\mathrm{SiO}_{2}{ }^{\mathrm{a}}$ & $\mathrm{Ag}-\mathrm{Ag}$ & 3.8 & 2.85 & 0.010 & & \\
\hline \multirow[t]{2}{*}{$\mathrm{Ag}_{2} \mathrm{O}$} & $\mathrm{Ag}-\mathrm{O}$ & 2 & 2.07 & 0.003 & 9.4 & 5 \\
\hline & $\mathrm{Ag}-\mathrm{Ag}$ & 6 & 3.37 & 0.027 & & \\
\hline $\mathrm{Ag}$ & $A g-A g$ & 12 & 2.86 & 0.009 & 2.3 & 6 \\
\hline
\end{tabular}

${ }^{\mathrm{a}}$ Used catalyst. 
Table 4. Oxidation of toluene with ${ }^{\mathrm{imp}} 10 \% \mathrm{Ag} / \mathrm{SiO}_{2}-900$ in the presence of ceria and carboxylic acid. Reaction conditions: $122 \mathrm{mmol}$ toluene, $3 \mathrm{~mol}-\%$ benzoic acid, $100 \mathrm{mg}$ biphenyl, $100 \mathrm{mg}{ }^{\mathrm{imp}} 10 \% \mathrm{Ag} / \mathrm{SiO}_{2}-900,10 \mathrm{bar}$ air $\left(4.2 \mathrm{mmol}_{2}\right)$, temperature as indicated, $1 \mathrm{~h}$ reaction time.

\begin{tabular}{ccccccc}
\hline \\
$140{ }^{\circ} \mathrm{C}$
\end{tabular}


Table 5. Oxidation of ethylbenzene with silver catalysts in the presence of $\mathrm{CeO}_{2}$ and carboxylic acid. Reaction conditions: $122 \mathrm{mmol}$ ethylbenzene, 3 mol-\% benzoic acid, $100 \mathrm{mg}$ biphenyl, $100 \mathrm{mg}$ catalyst, oxygen atmosphere, reflux, $3 \mathrm{~h}$ reaction time.

\begin{tabular}{|c|c|c|c|c|c|c|}
\hline & & & & & & \\
\hline Catalyst & & & & & TON & Entry \\
\hline${ }^{\mathrm{imp}} 10 \% \mathrm{Ag} / \mathrm{SiO}_{2}-900$ & 4.4 & 11.8 & 4.1 & 20.3 & 290 & 1 \\
\hline${ }^{\mathrm{FSP}} 1 \% \mathrm{Ag} / 10 \% \mathrm{Ce} / \mathrm{SiO}_{2}$ & 4.0 & 6.8 & 4.2 & 15.0 & 2000 & 2 \\
\hline${ }^{\mathrm{FSP}} 1 \% \mathrm{Ag} / 30 \% \mathrm{Ce} / \mathrm{SiO}_{2}$ & 2.0 & 3.8 & 6.0 & 11.8 & 1600 & 3 \\
\hline${ }^{\mathrm{FSP}} 1 \% \mathrm{Ag} / 50 \% \mathrm{Ce} / \mathrm{SiO}_{2}$ & 1.7 & 3.2 & 1.8 & 6.7 & 890 & 4 \\
\hline $\mathrm{SiO}_{2}$ & $<0.1$ & $<0.1$ & 0.8 & 0.9 & - & 5 \\
\hline
\end{tabular}


Table 6. Oxidation of cumene with silver catalysts in the presence of $\mathrm{CeO}_{2}$ and carboxylic acid. Reaction conditions: $122 \mathrm{mmol}$ cumene, $3 \mathrm{~mol}-\%$ benzoic acid, $100 \mathrm{mg}$ biphenyl, $100 \mathrm{mg}$ catalyst, $140{ }^{\circ} \mathrm{C}, 3 \mathrm{~h}$ reaction time.

\begin{tabular}{|c|c|c|c|c|c|c|}
\hline & & & & & & \\
\hline Catalyst & & & & Combined & TON & Entry \\
\hline${ }^{\mathrm{imp}} 10 \% \mathrm{Ag} / \mathrm{SiO}_{2}-900$ & 4.2 & 9.1 & 9.5 & 22.8 & 330 & 1 \\
\hline${ }^{\mathrm{FSP}} 1 \% \mathrm{Ag} / 10 \% \mathrm{Ce}-\mathrm{SiO}_{2}$ & 1.6 & 0.1 & 0.6 & 2.3 & 310 & 2 \\
\hline${ }^{\mathrm{FSP}} 1 \% \mathrm{Ag} / 30 \% \mathrm{Ce}-\mathrm{SiO}_{2}$ & 1.7 & 0.1 & 0.5 & 2.3 & 310 & 3 \\
\hline${ }^{\mathrm{FSP}} 1 \% \mathrm{Ag} / 50 \% \mathrm{Ce}-\mathrm{SiO}_{2}$ & 2.4 & 0.1 & 0.4 & 2.9 & 390 & 4 \\
\hline $\mathrm{SiO}_{2}$ & $<0.1$ & 0.1 & 1.7 & 1.8 & - & 5 \\
\hline
\end{tabular}




\section{Schemes}

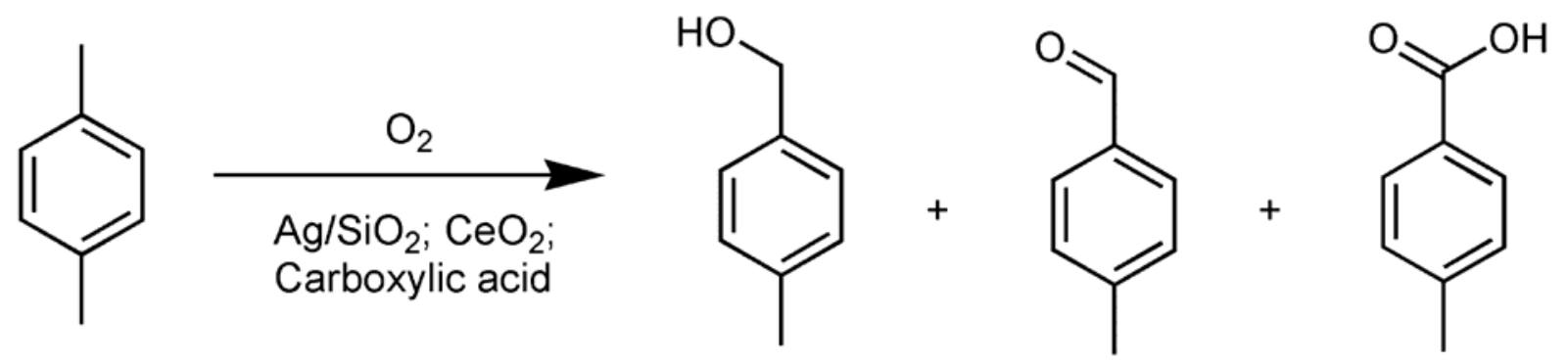

Scheme 1. Oxidation of $p$-xylene with molecular oxygen catalyzed by $\mathrm{Ag} / \mathrm{SiO}_{2}$ in the presence of ceria and a carboxylic acid. 


\section{Step 1}

Step 2

Step 3

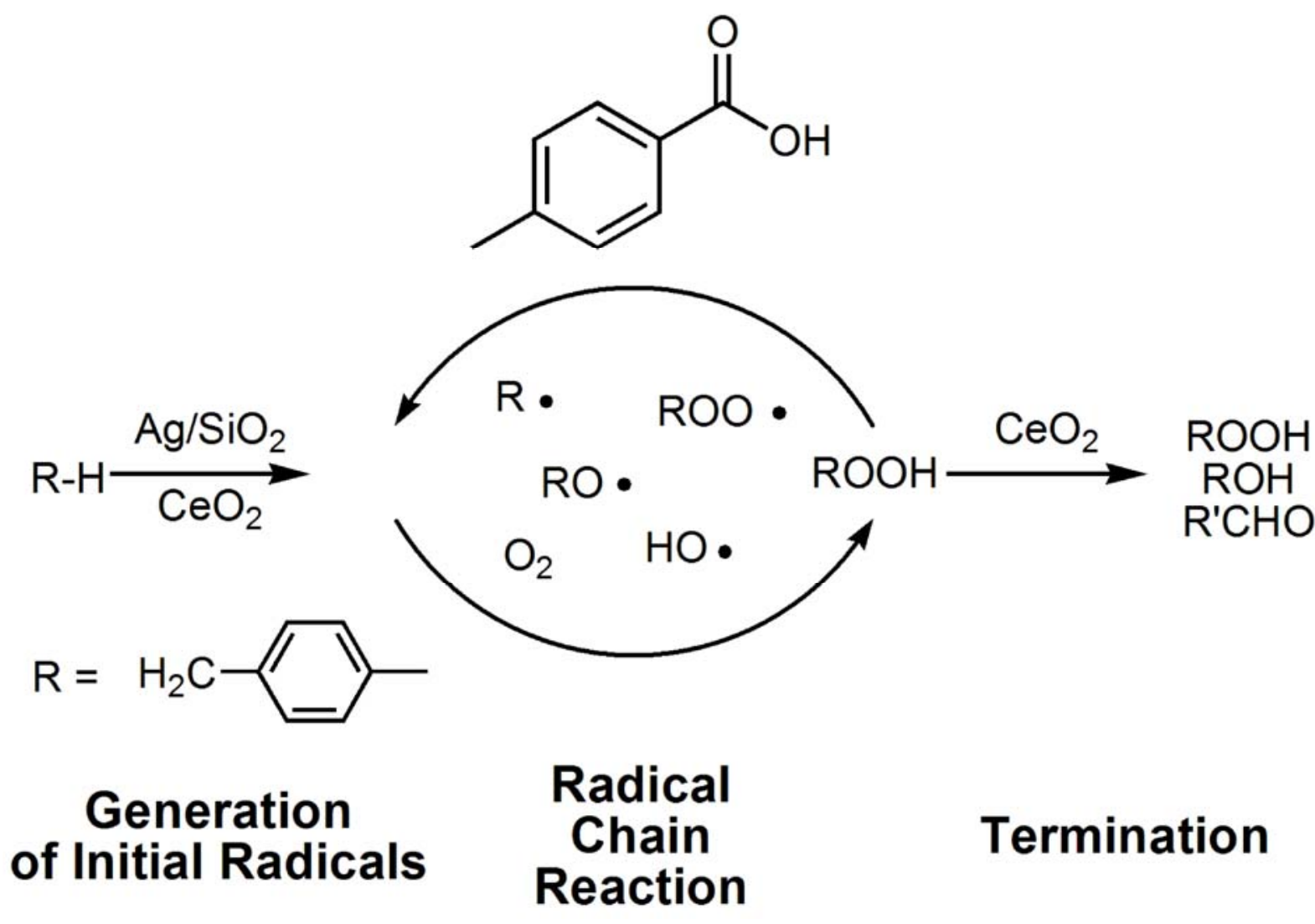

Scheme 2. Schematic reaction sequence in the radical autoxidation of $p$-xylene and potential roles of Ag, $\mathrm{CeO}_{2}$ and $p$-toluic acid promoters. 
Figures

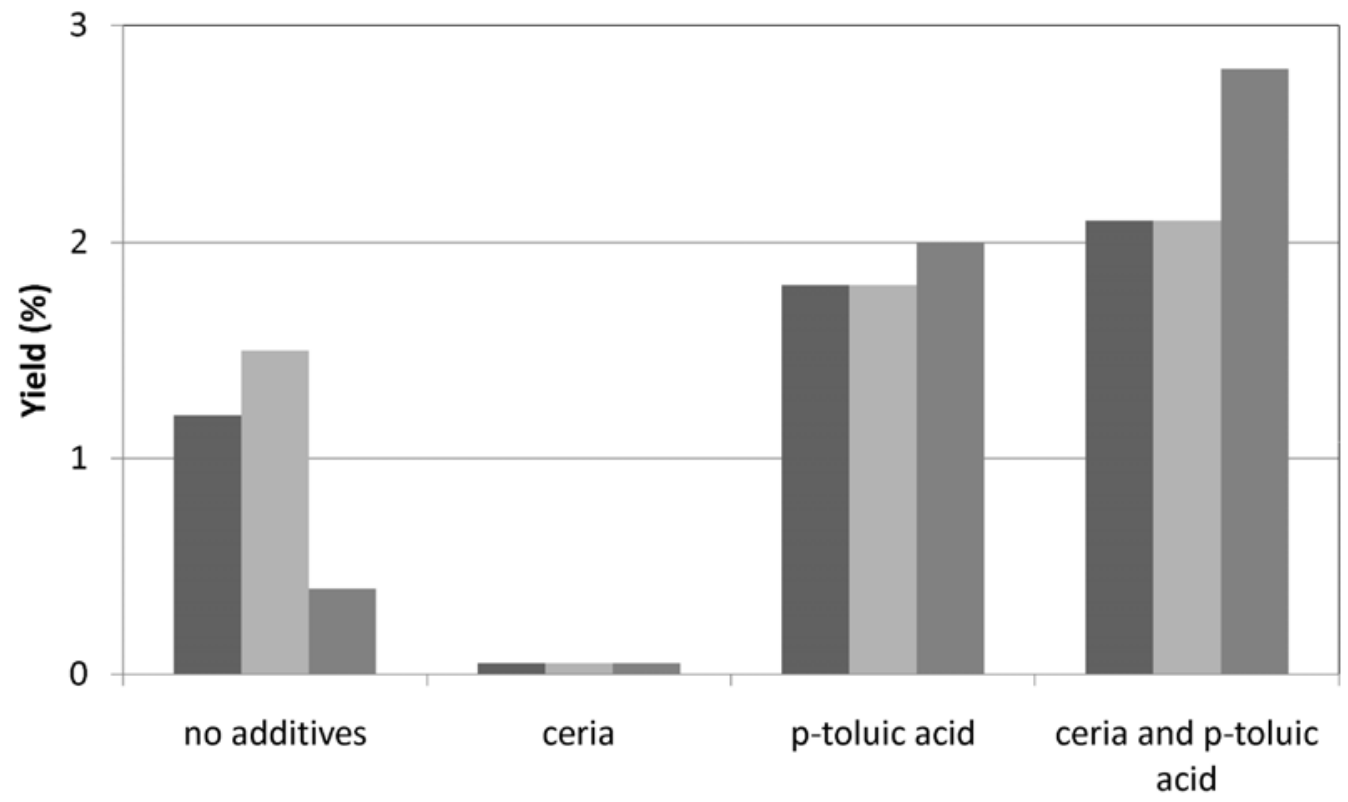

-p-methylbenzyl alcohol $\quad$ p-methyl benzaldehyde $\quad$ p-toluic acid

Fig. 1. 


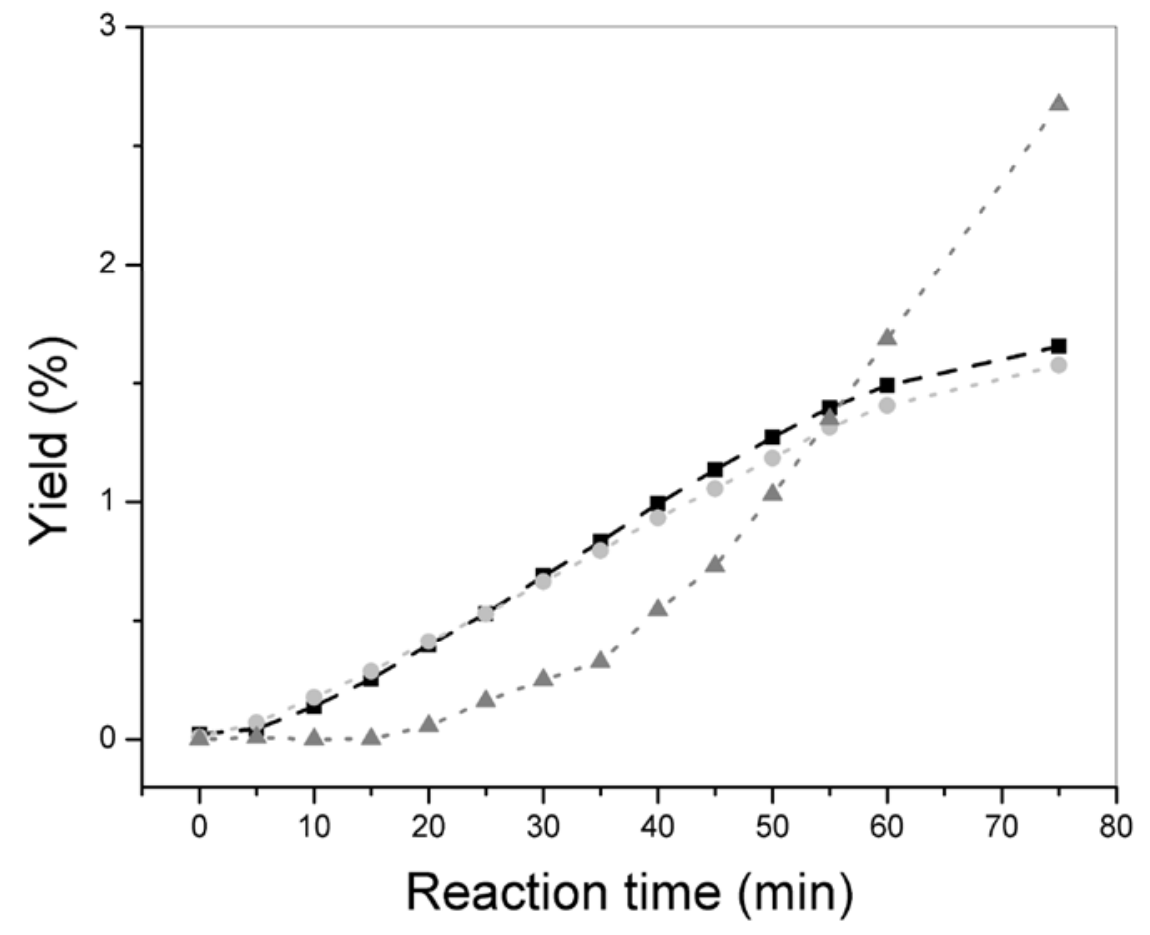

Fig. 2. 


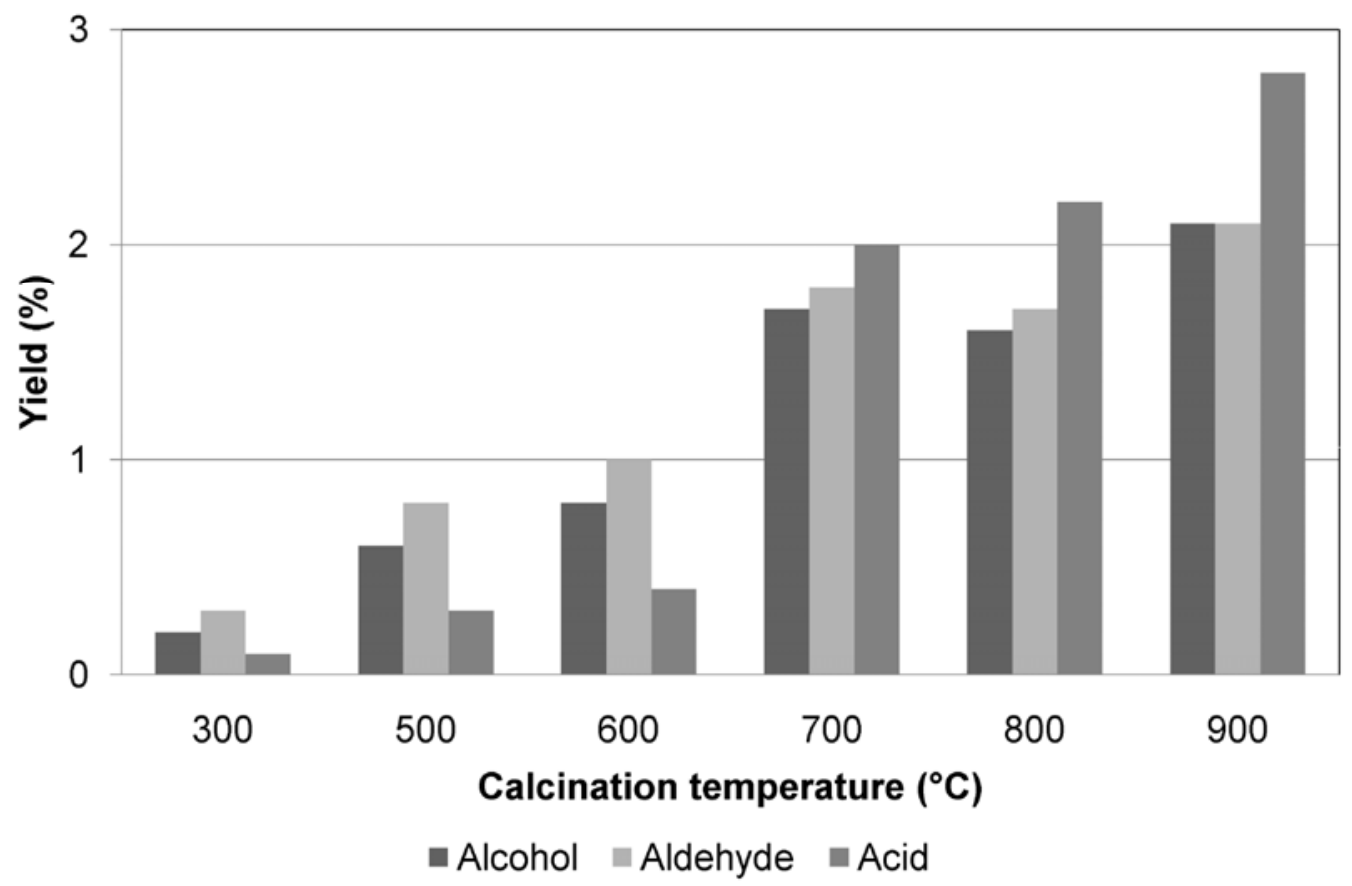

Fig. 3. 


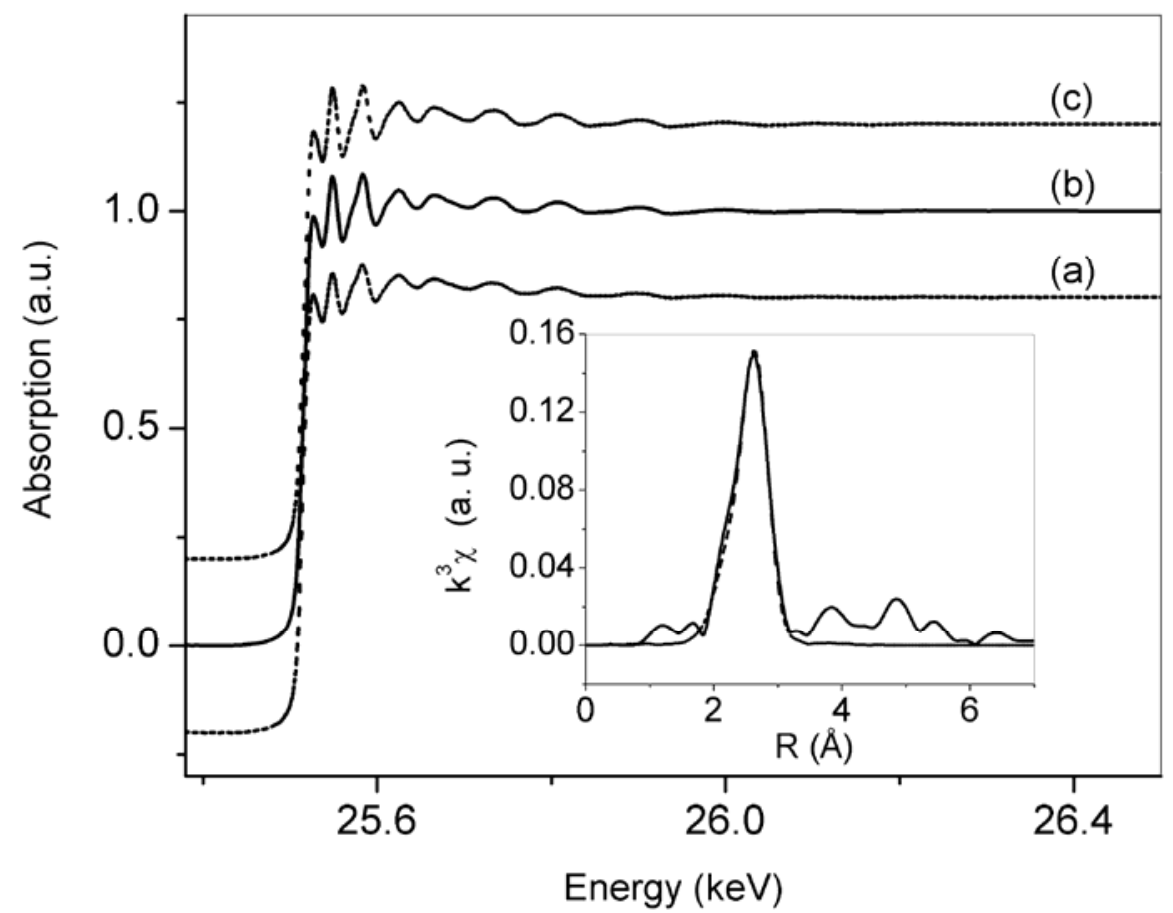

Fig. 4. 


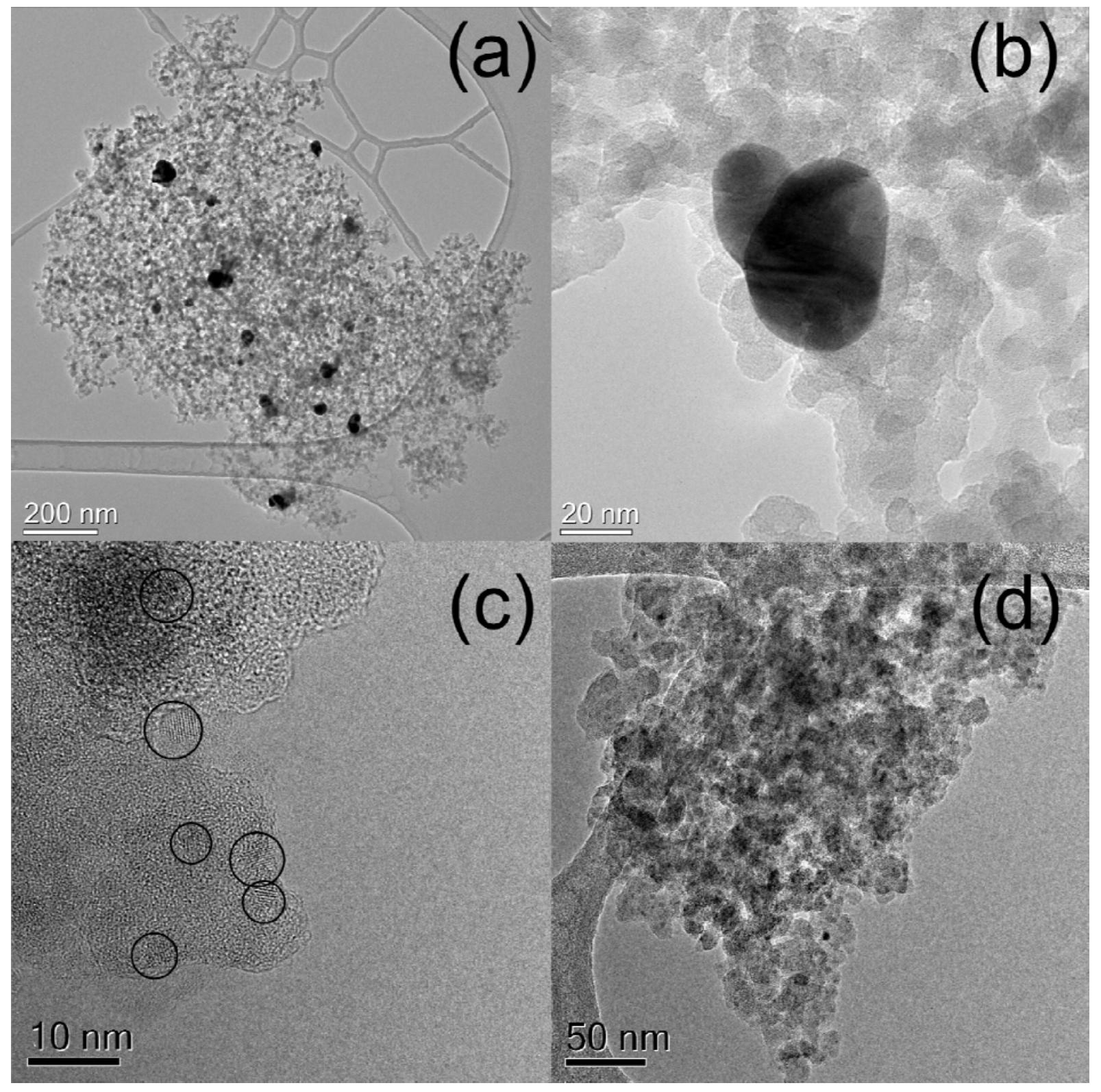

Fig. 5. 

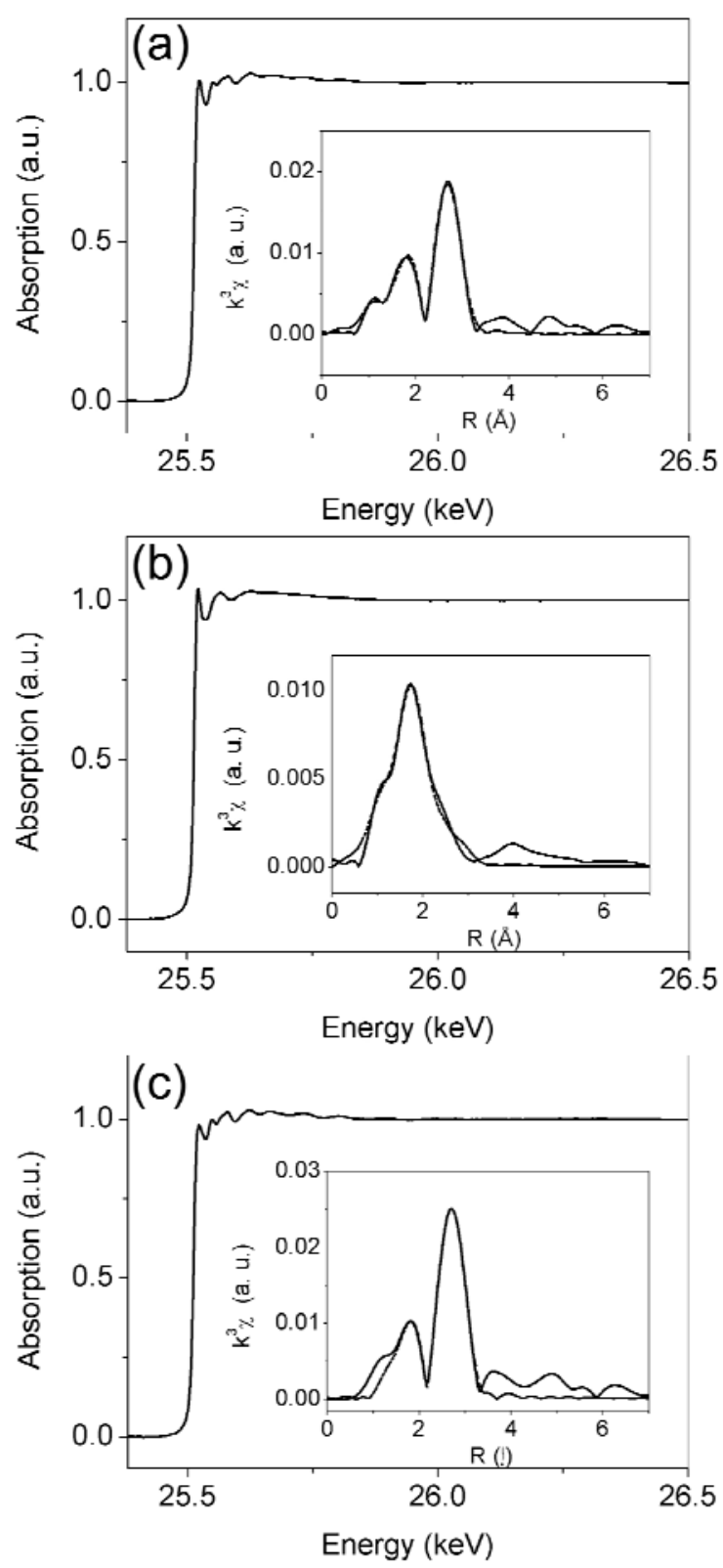

Fig. 6. 


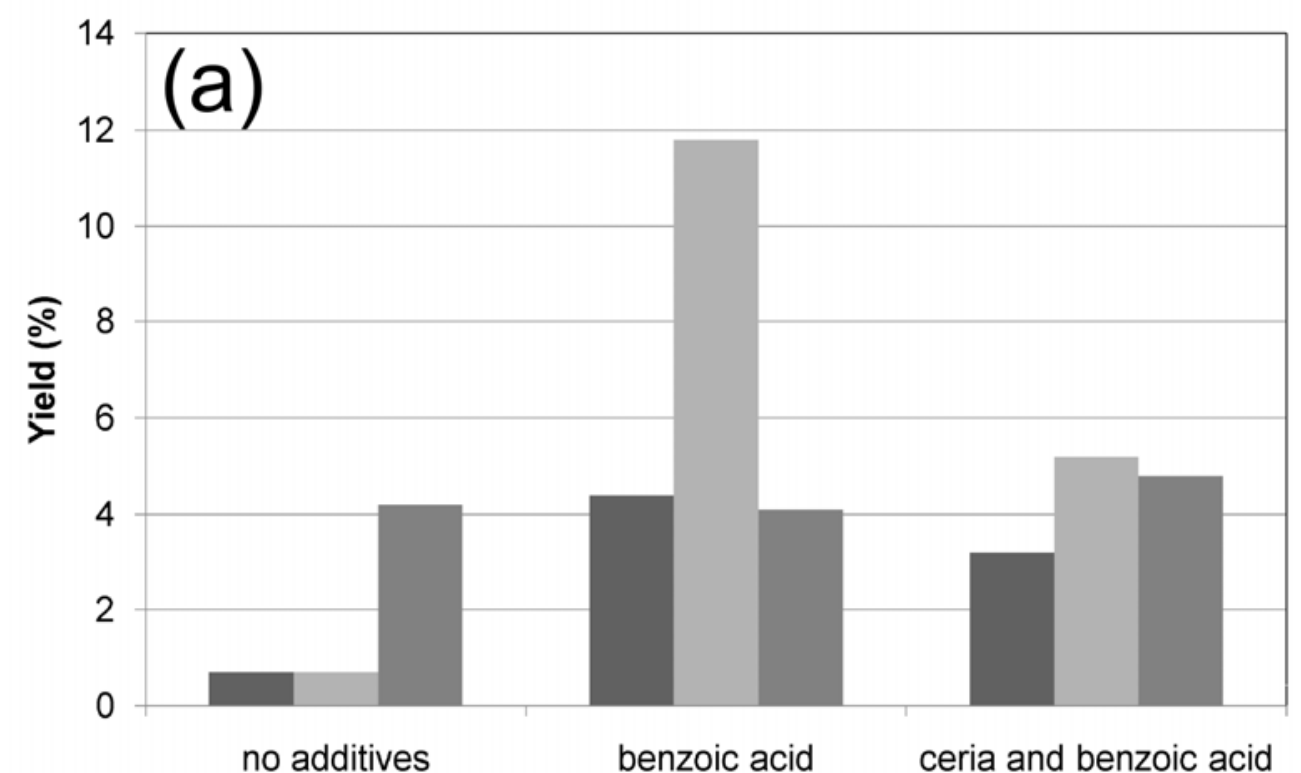

घ1-phenylethanol acetophenone athylbenzene hydroperoxide

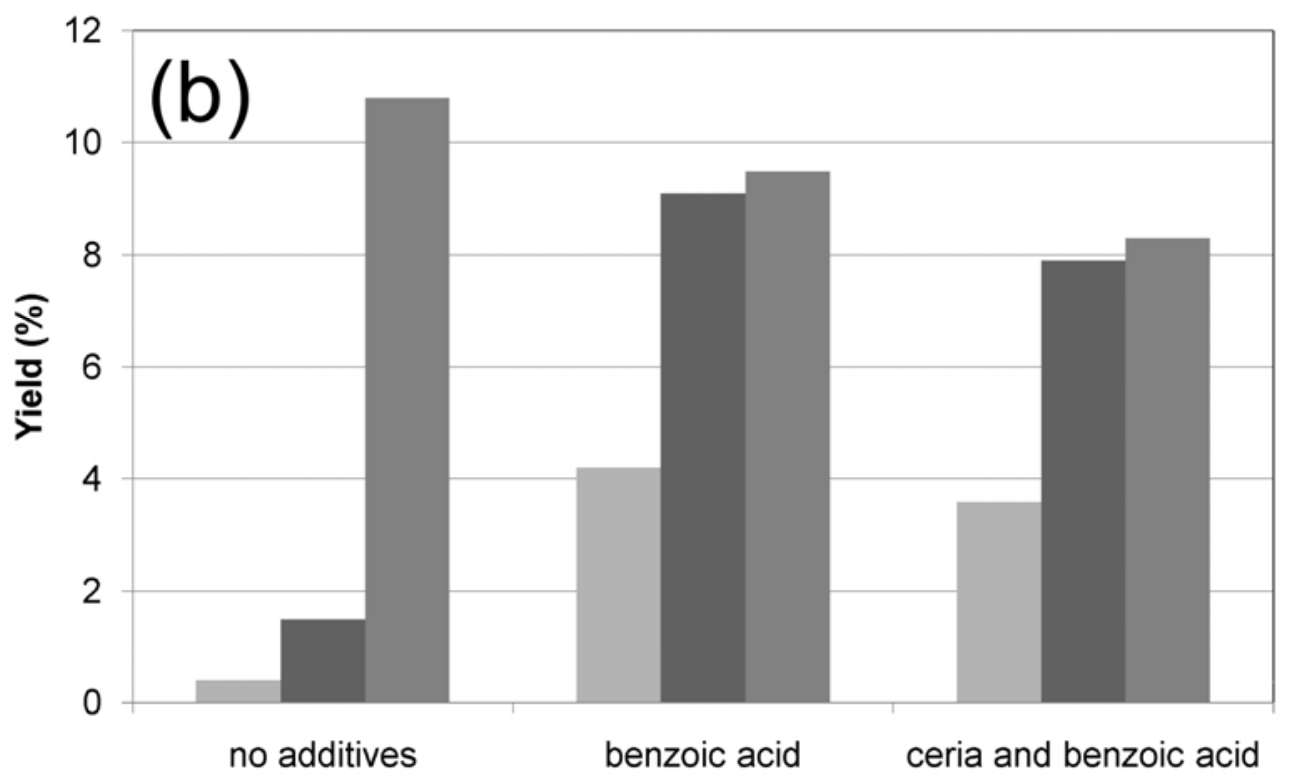

= acetophenone $\quad$ 2-phenylpropan-2-ol = cumene hydroperoxide

Fig. 7. 